US Army Corps of Engineers ${ }_{\circledast}$

Engineer Research and Development Center

Effects of Adding Barge Lanes Along Houston Ship Channel Through Galveston Bay, Texas

Alex R. Carrillo, M. Soraya Sarruff, and R. C. Berger

September 2002

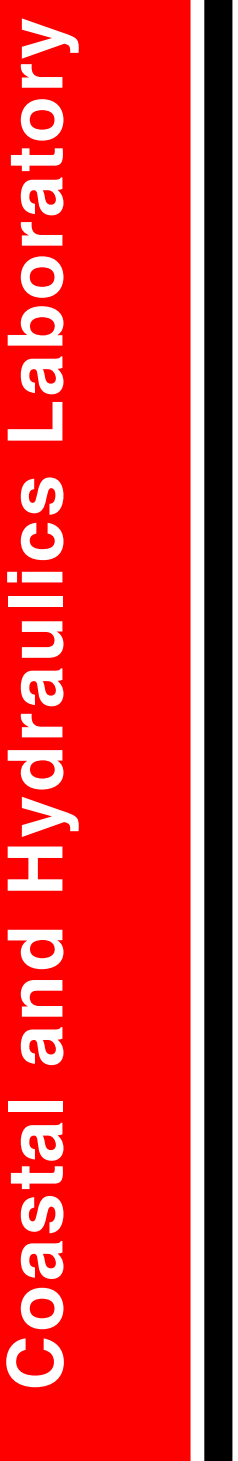


The contents of this report are not to be used for advertising, publication, or promotional purposes. Citation of trade names does not constitute an official endorsement or approval of the use of such commercial products.

The findings of this report are not to be construed as an official Department of the Army position, unless so designated by other authorized documents. 


\section{Effects of Adding Barge Lanes Along Houston Ship Channel Through Galveston Bay, Texas}

by Alex R. Carrillo, M. Soraya Sarruff, R. C. Berger

Coastal and Hydraulics Laboratory

U.S. Army Engineer Research and Development Center 3909 Halls Ferry Road

Vicksburg, MS 39180-6199

Final report

Approved for public release; distribution is unlimited

Prepared for U.S. Army Engineer District, Galveston

P.O. Box 1229, Galveston, TX 77553-1229 


\section{Contents}

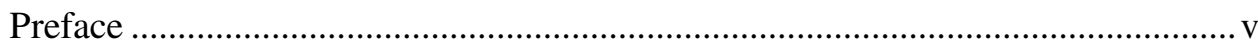

Conversion Factors, Non-SI to SI Units of Measurement .......................................vi

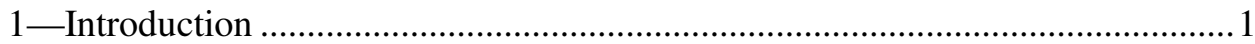

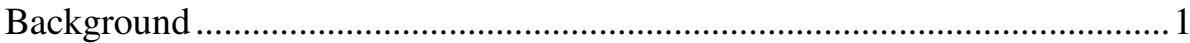

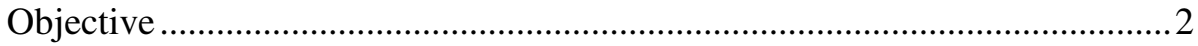

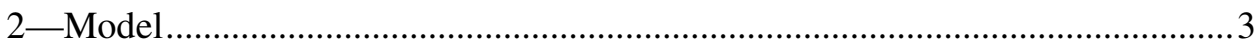

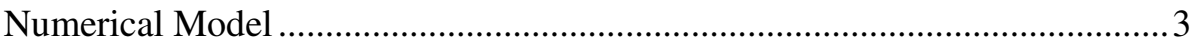

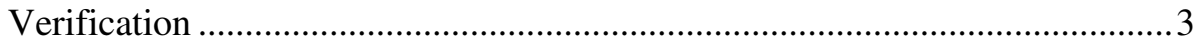

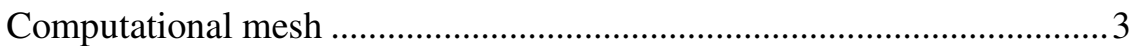

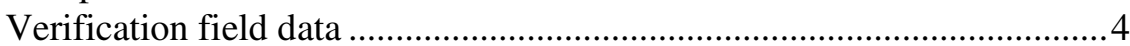

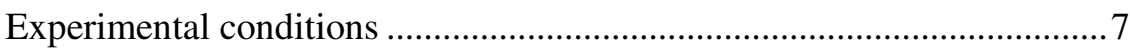

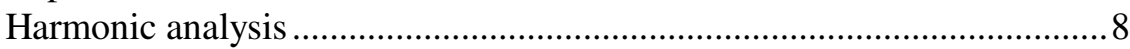

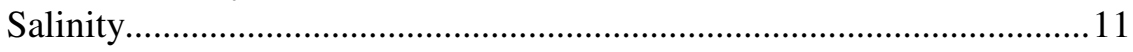

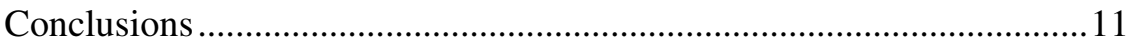

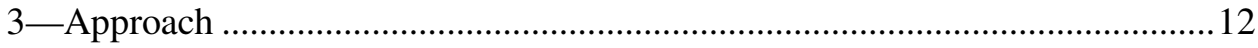

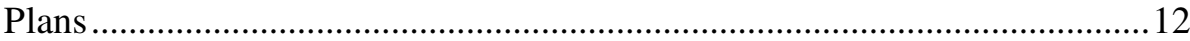

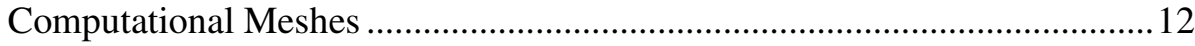

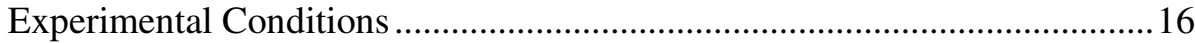

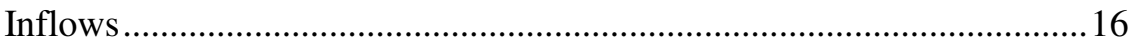

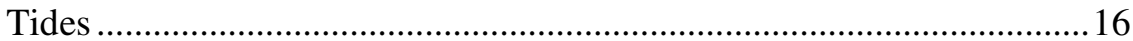

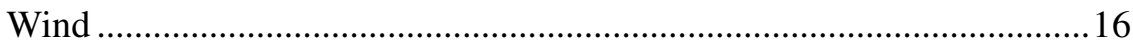

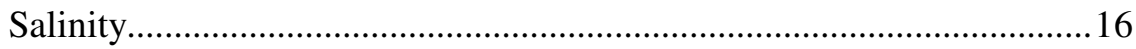

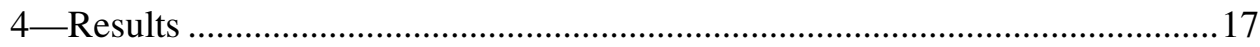

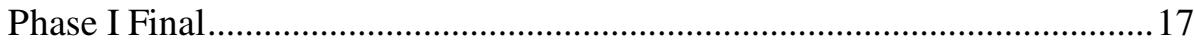

Phase I as Built and Phase I as Built with Barge Lanes.................................. 17

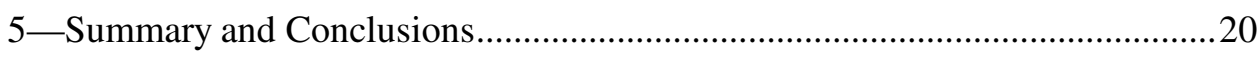

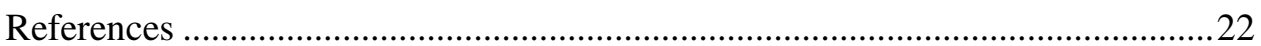

Plates 1-25

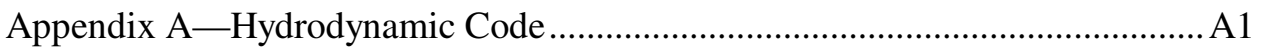

SF 298 


\section{List of Tables}

Table 1.

Mesh Sizes

Table 2. $\quad$ Modeled Month Average Salinities, for Phase I as Built and Phase I as Built with Barge Lanes, for Select Grid

Locations

\section{List of Figures}

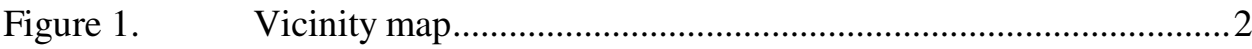

Figure 2. Computational mesh -1990 existing conditions for verification .......................................................................... 4

Figure 3. Basic long-term survey data collection equipment locations (sta S1.0, S2.0, S5.5, S6.0, S8.1, S9.0, S11.1, $\mathrm{S} 12.0$, and $\mathrm{S} 15.1$ record salinity as well) 5

Figure 4. Supplementary long-term data collection equipment

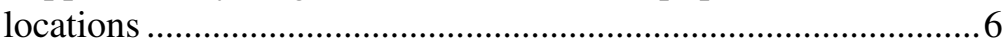

Figure 5. Intensive survey data collection boat ranges ..............................

Figure 6. Prototype/model tidal amplitude comparison for K1 constituent

Figure 7. Prototype/model tidal amplitude comparison for $\mathrm{O} 1$

Figure 8. Comparison of prototype and model phase lag for K1 constituent

Figure 9. Comparison of prototype and model phase lag for $\mathrm{O} 1$ constituent

Figure 10. Computational mesh - phase I as studied in prior model study

Figure 11. Computational mesh - phase I as built

Figure 12. Computational mesh - phase I as built with addition of barge lanes 15

Figure 13. Select grid locations for comparison of phase I as built and phase I as built with barge lanes 


\section{Preface}

This report presents the results of a numerical model investigation used to predict average salinity changes that will occur in the Galveston Bay region as a result of the addition of barge lanes along the Houston Ship Channel.

This investigation was conducted from September 2000 through May 2001 at the U.S. Army Engineer Research and Development Center (ERDC) by Dr. R. C. Berger, Mr. A. R. Carrillo, Ms. M. S. Sarruff, and Mr. J. A. Sanchez of the Coastal and Hydraulics Laboratory (CHL). Funding was provided by the U.S. Army Engineer District, Galveston.

The work was performed under the general direction of Mr. Thomas W. Richardson, Director, CHL, and Dr. R. T. McAdory, Chief, Tidal Hydraulics Branch, CHL.

At the time of publication of this report, Dr. James R. Houston was Director of ERDC, and COL John W. Morris III, EN, was Commander and Executive Director.

The contents of this report are not to be used for advertising, publication, or promotional purposes. Citation of trade names does not constitute an official endorsement or approval of the use of such commercial products. 


\section{Conversion Factors, Non SI to SI Units of Measurement}

Non-SI units of measurement used in this report can be converted to SI units as follows:

\begin{tabular}{|l|l|l|}
\hline Multiply & By & To Obtain \\
\hline \hline cubic feet & 0.02831685 & cubic meters \\
\hline feet & 0.3048 & meters \\
\hline miles (U.S. statute) & 1.609347 & kilometers \\
\hline square feet & 0.09290304 & square meters \\
\hline
\end{tabular}




\section{Introduction}

\section{Background}

The U.S. Army Engineer District, Galveston, is making an investigation of the addition of barge lanes along the Houston Ship Channel through Galveston Bay, TX. In the early to mid 1990s the U.S. Army Engineer Research and Development Center (ERDC), Coastal and Hydraulics Laboratory (CHL) produced a three-dimensional (3-D) numerical model of Galveston Bay to study the enlargement of the Houston Ship Channel from nominal dimensions of $40 \mathrm{ft}^{1}$ deep mlw by a 400 -ft-width (base) to 45 -ft-deep channel with a $530-\mathrm{ft}$ width (phase I) (Berger et al. 1995a). The model produced water surface, velocity, and salinity fields for the base and phase I conditions. These data in turn were used to make an environmental assessment. The channel is presently being dredged to phase I dimensions.

The proposed barge lanes are to allow barge traffic to safely coexist with the deep-draft navigation. These lanes are to be along and on both sides of the channel throughout Galveston Bay. The barge lanes are to have a 14-ft required depth and extend $500 \mathrm{ft}$ from the center line of the navigation channel. The Galveston District requested that the Galveston Bay model be used to provide salinity, velocity, and water surfaces in support of an environmental assessment.

The Galveston Bay model consists of the finite element mesh, the data, and the hydrodynamic code. The finite element mesh represents the spatial grid and bathymetry. The model was updated to match the "as built" conditions. These include the actual disposal configuration, the Bayport Channel bathymetry, and the actual dredged channel depths for the Houston Ship Channel. The data includes the boundary conditions and forcing data (winds, Coriolis, etc.). The hydrodynamic code used has evolved since the prior investigation with the addition of sediment transport, Smagorinsky horizontal diffusion, and improved Newton iteration, among several items. That particular code is now referred to as TABS-MDS.

\footnotetext{
${ }^{1}$ A table of factors for converting non-SI units of measurement to SI units is presented on page vi.
} 


\section{Objective}

The objective of the work presented herein is to predict the month-average salinity changes that will occur in Galveston Bay (Figure 1), resulting from the addition of the proposed barge lanes. The tasks undertaken, and presented herein are:

a. Provide a short check of the verification using the TABS-MDS code.

b. Incorporate all features of the as built phase I.

c. Modify the grid to include the barge lane configuration.

d. Run three plans for one hydrologic year each. The three plans are:

(1) Phase I as studied in the prior model study.

(2) Phase I as built.

(3) Phase I as built with the addition of the barge lanes.

Since a low-flow hydrologic scenario is regarded as the most critical, the "present"' low-flow boundary conditions are utilized.

The purpose of this report is to present the results of a numerical model investigation addressing this objective. Galveston Bay is the modeled region including Trinity Bay, East Bay, and West Bay, as shown in Figure 1.

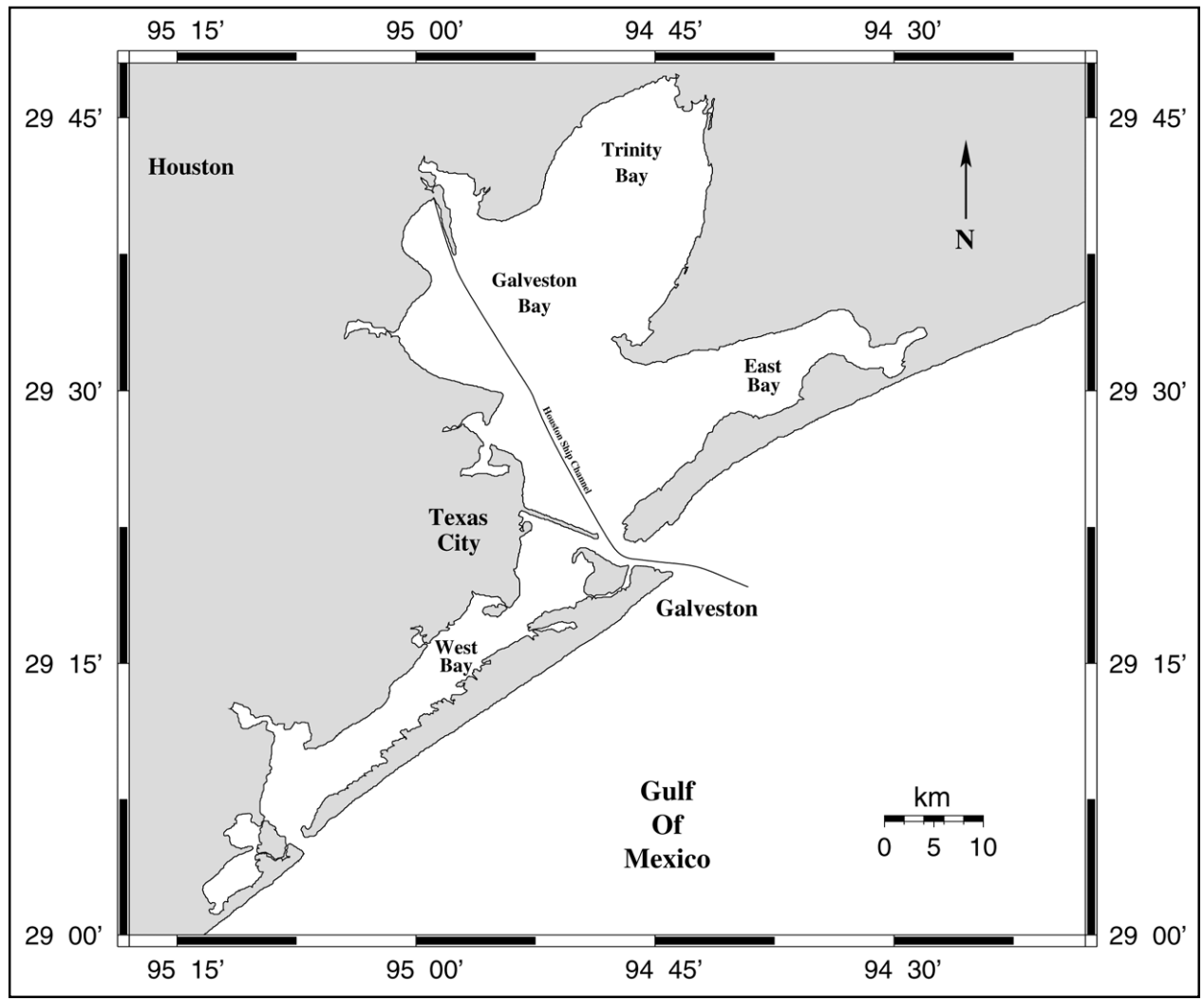

Figure $1 . \quad$ Vicinity map 


\section{Model}

\section{Numerical Model}

TABS-MDS, the numerical model used for this investigation, is a 3-D finite element code originally developed by Dr. Ian King of Resource Management Associates, and modified at ERDC. It models 3-D hydrodynamics and salt transport accounting for unsteady river inflows, tides, wind effects, and densitydriven circulation. It has been widely used by ERDC to model 3-D hydrodynamics and salinity at numerous locations, including Galveston Bay, TX (Berger et al. 1995a, 1995b). The model is described more fully in Appendix A.

\section{Verification}

The TABS-MDS numerical model has evolved since the prior Galveston Bay verification, so a short reverification check was performed using the same boundary conditions and bathymetry as the original study (Berger et al. 1995a). This will provide the District with an up-to-date model that can be used for any hydrodynamic modeling of the bay. A brief discussion of the specifics of the experimental conditions are addressed in the following sections. For a more detailed discussion see Berger et al. 1995a.

\section{Computational mesh}

The verification check consists of using the current updated TABS-MDS code for the verification period used in the original model verification (Berger et al. 1995a). The channel configuration for the verification check is that of the 40 $\times 400-\mathrm{ft}$ channel that existed when the field data were collected. Figure 2 illustrates the planform view of the computational mesh used. The mesh represents the 1990 existing conditions. The grey areas denote the 3-D regions of the mesh. The mesh consists of 12,710 nodes and 4,422 elements. (The mesh was refined near the channel compared to the earlier model study.) 


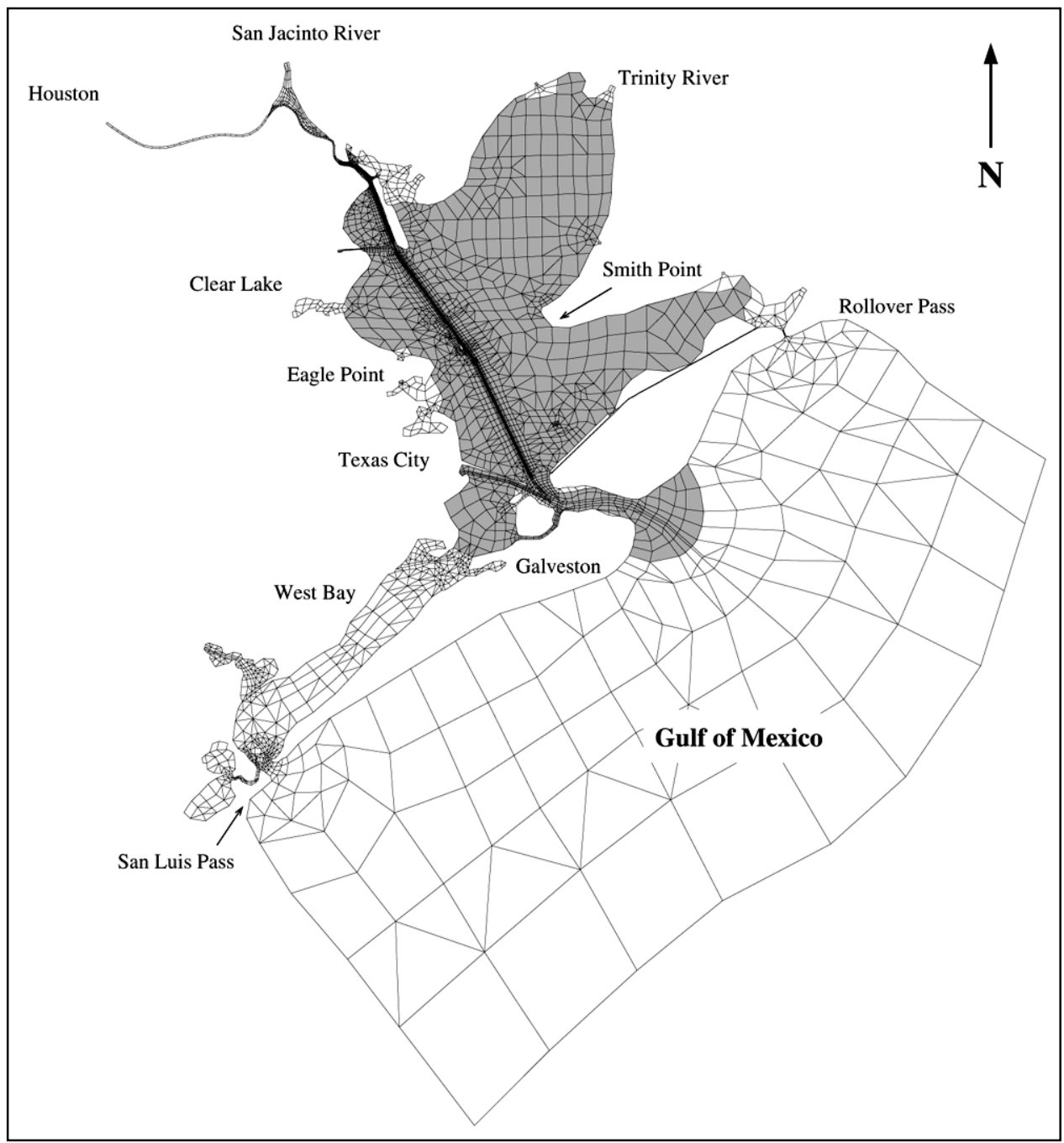

Figure 2. Computational mesh - 1990 existing conditions for verification

\section{Verification field data}

Field data collection occurred from 19 July 1990 to 15 January 1991. The bulk of these data was collected by moored salinity and velocity meters, as well as tide gauges mounted throughout the system (Figures 3 and 4). Within this 6month time, a short-duration intense field data collection was conducted 19-20 July 1990. These data included velocity and salinity measurements over depth at five ranges along the navigation channel (See Figure 5). Complete details of the field collection may be found in Fagerburg et al. (1994). 


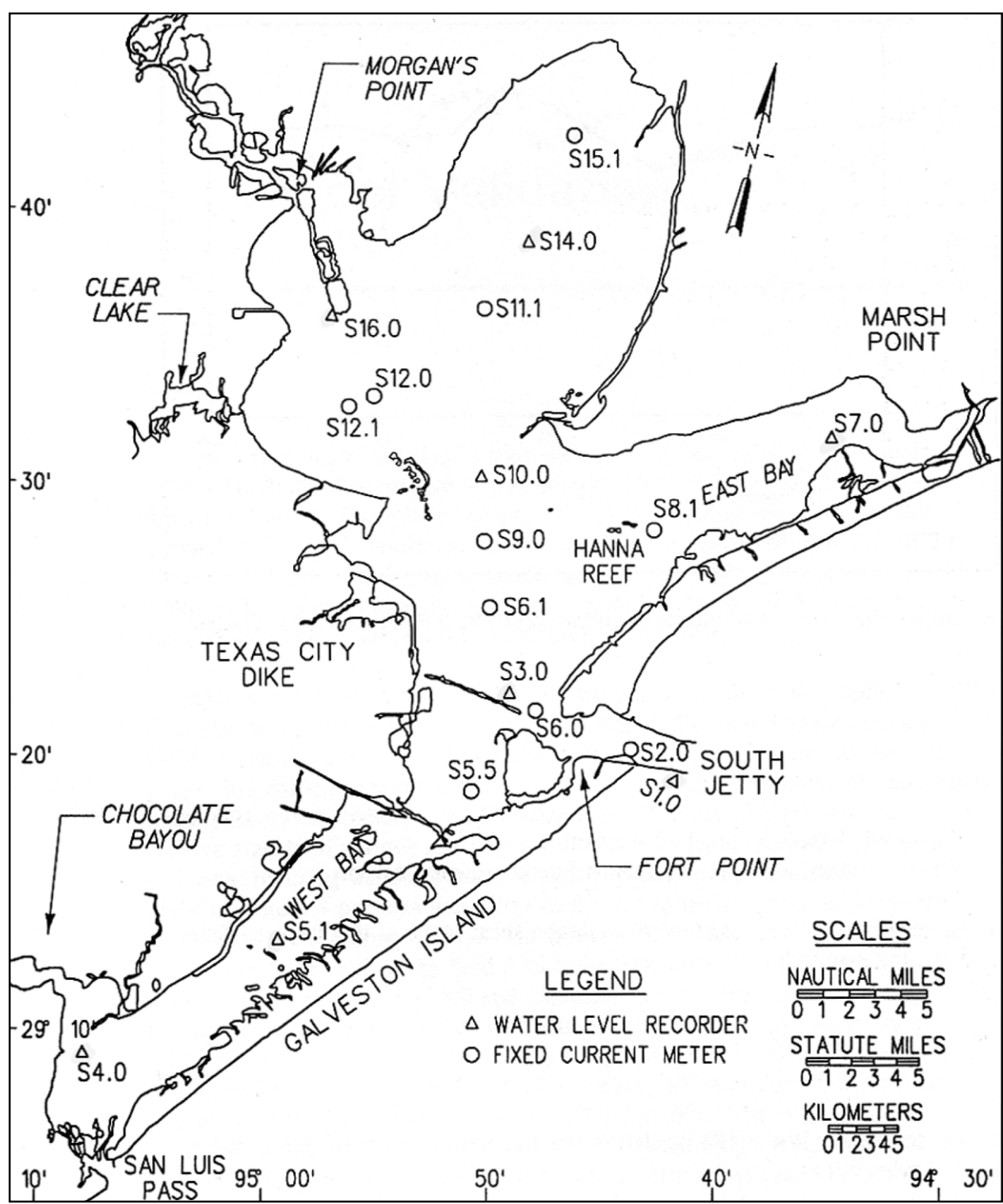

Figure 3. Basic long-term survey data collection equipment locations (sta S1.0, S2.0, S5.5, S6.0, S8.1, S9.0, S11.1, S12.0, and S15.1 record salinity as well) 


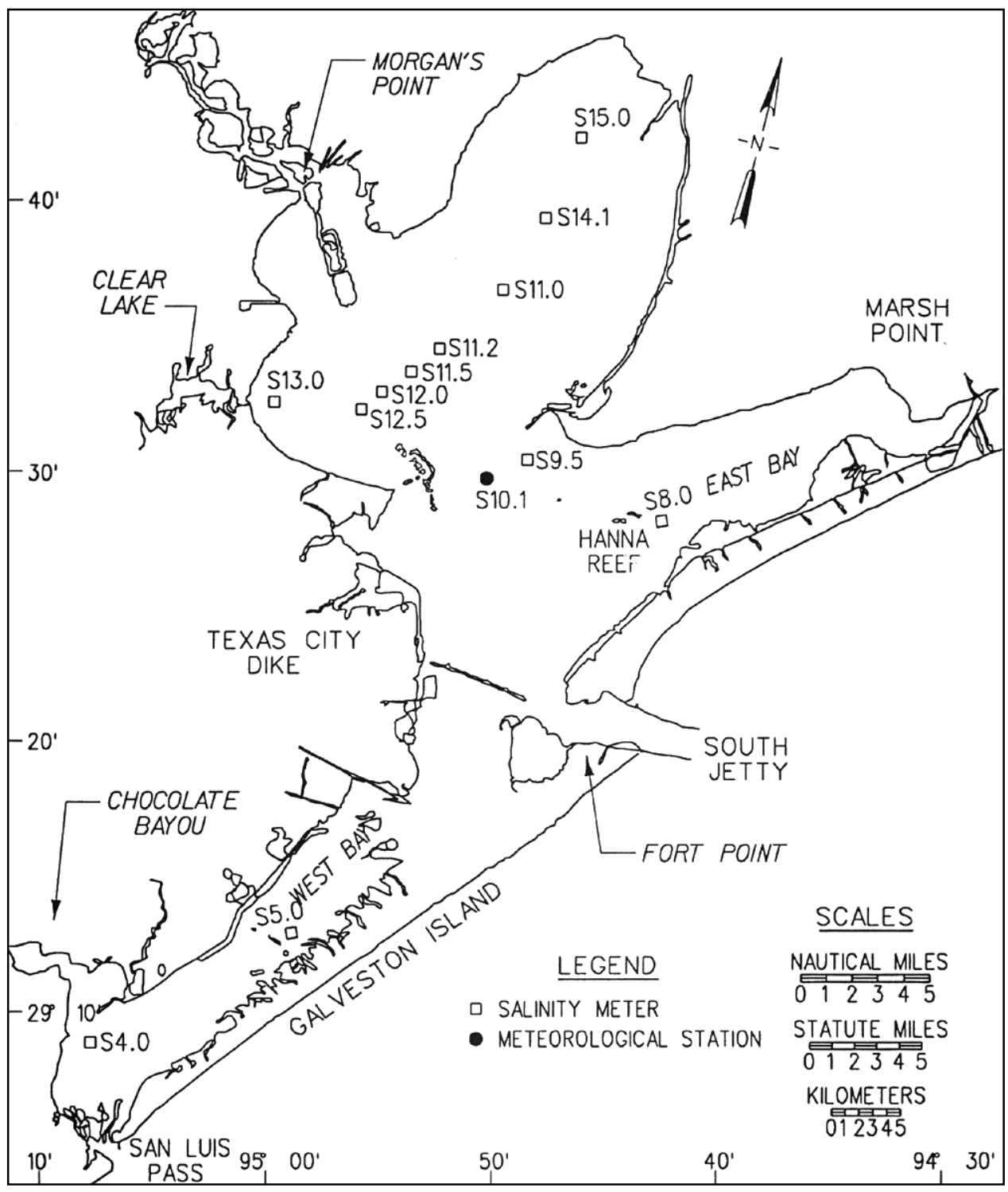

Figure 4. Supplementary long-term data collection equipment locations 


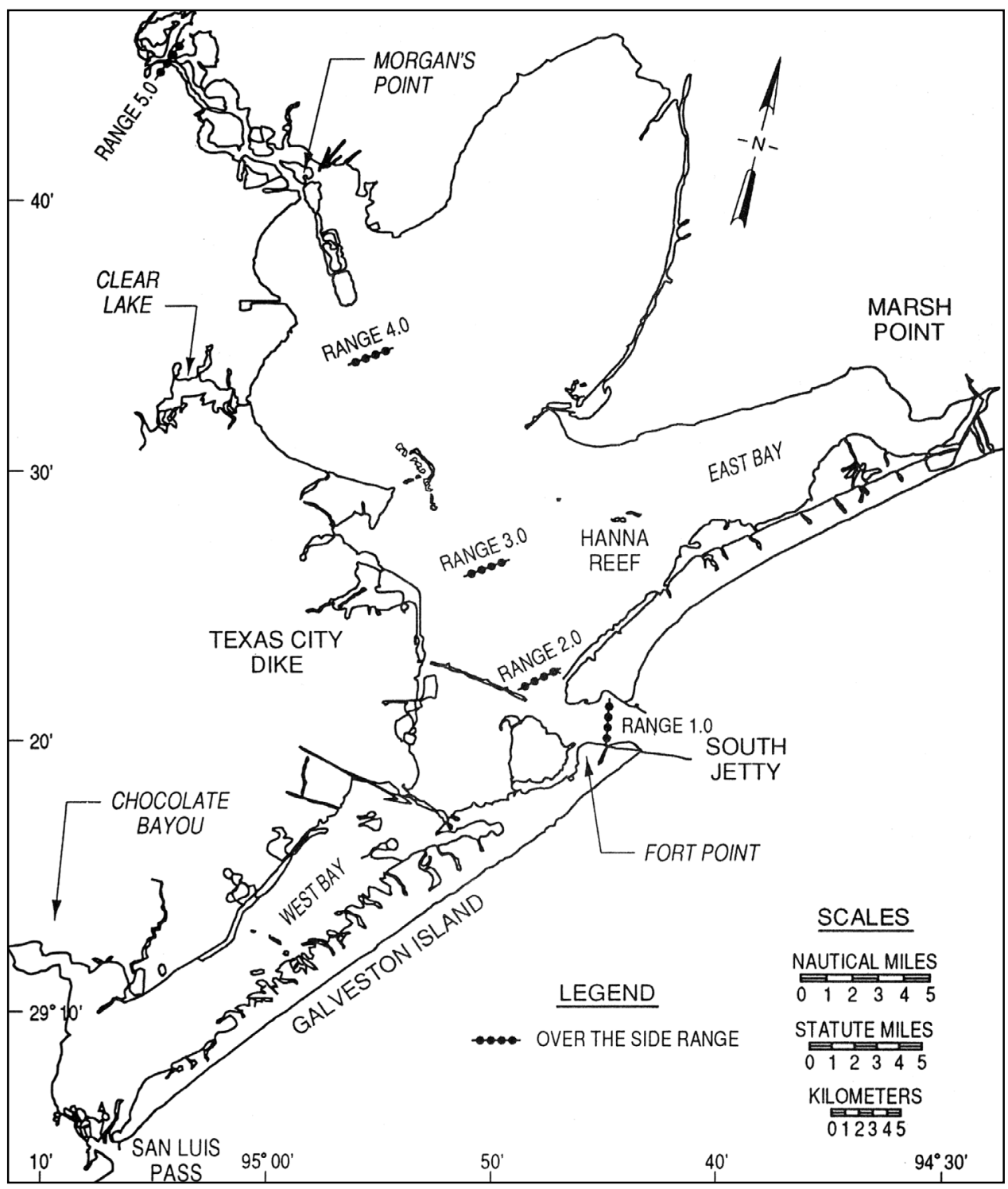

Figure 5. Intensive survey data collection boat ranges

\section{Experimental conditions}

The data used to drive the model tide were the National Ocean Service/ National Oceanic and Atmospheric Administration (NOS/NOAA) sta 877-1510. Pleasure Pier tide gauge data shifted forward $1.31 \mathrm{hr}$ to account for the model boundary approximately 26 miles offshore from Pleasure Pier. The actual data were filtered to remove signals of periods less than $3 \mathrm{hr}$. The salinity at the boundary was estimated by using the published averages supplied by Cochrane and Kelly (1986). The wind data were provided by two sources. ERDC established a meteorological station at location S10.1 (Figure 4) for period 19 July 1990 to 15 January 1991. The National Weather Service data at Houston International Airport were also obtained for this period. A correlation was derived between the National Weather Service and ERDC data so that readings at Houston International could be used for Galveston Bay (see Berger et al. 1995a). 
The model must be run for a length of time, termed spin-up, to remove initial conditions error. The closer that the initial salinity field is to the ultimate field, the less length of time is required for spin-up. Therefore, the verification initial salinity field for January 1990 was generated by interpolating actual field data. This rough approximation was sufficient since the verification field data occurred in July, giving a sufficient relaxation time for the data.

The numerical model calculated water-surface elevations, current velocities (3-D components), and salinities at each node every $30 \mathrm{~min}$ for the 12-month period of simulation between January 1 and December 31 .

\section{Harmonic analysis}

A tidal signal can be affected by a number of factors, including astronomical as well as meteorological ones. Tidal behavior is therefore better understood after removing variable unpredictable events, such as wind-driven magnitudes and random meteorological effects. A harmonic analysis of the tidal record can remove the factors mentioned, while exposing the major tidal components. The resulting amplitude and phase prove to be useful tools when evaluating the performance of a numerical model, related to tide approximations.

Sta S1.0, S3.0, and S16.0 were selected for analysis (See Figure 3). An 8week period spanning August 25 through October 27, 1990, was extracted from each station record. The model data were in $0.5-\mathrm{hr}$ increments, while the prototype data varied. That is, sta S1.0 was recorded every $0.5 \mathrm{hr}$; sta S3.0 was recorded in $0.24-\mathrm{hr}$ increments. Finally, sta S16.0 was recorded in $0.25-\mathrm{hr}$ increments. The data were filtered to remove periods less than $3 \mathrm{hr}$ and greater than $35 \mathrm{hr}$. The filtering process yielded data sets comprising primarily diurnal and semidiurnal components, as well as overtides.

The harmonic analysis results in a list of amplitudes and phases corresponding to diurnal and semidiurnal constituents. For the purposes of this study, only diurnal constituents were used in our comparison of prototype and model. After observing the resulting constituents, two diurnal components dominated the tidal range, $\mathrm{K} 1$ and $\mathrm{O} 1$, corresponding to periods of 23.93 and $25.92 \mathrm{hr}$, respectively. A ratio of the amplitude of $\mathrm{K} 1$ and $\mathrm{O} 1$ at each station to that of sta S1.0, or relative amplitude, was calculated and charted on Figures 6 and 7. 


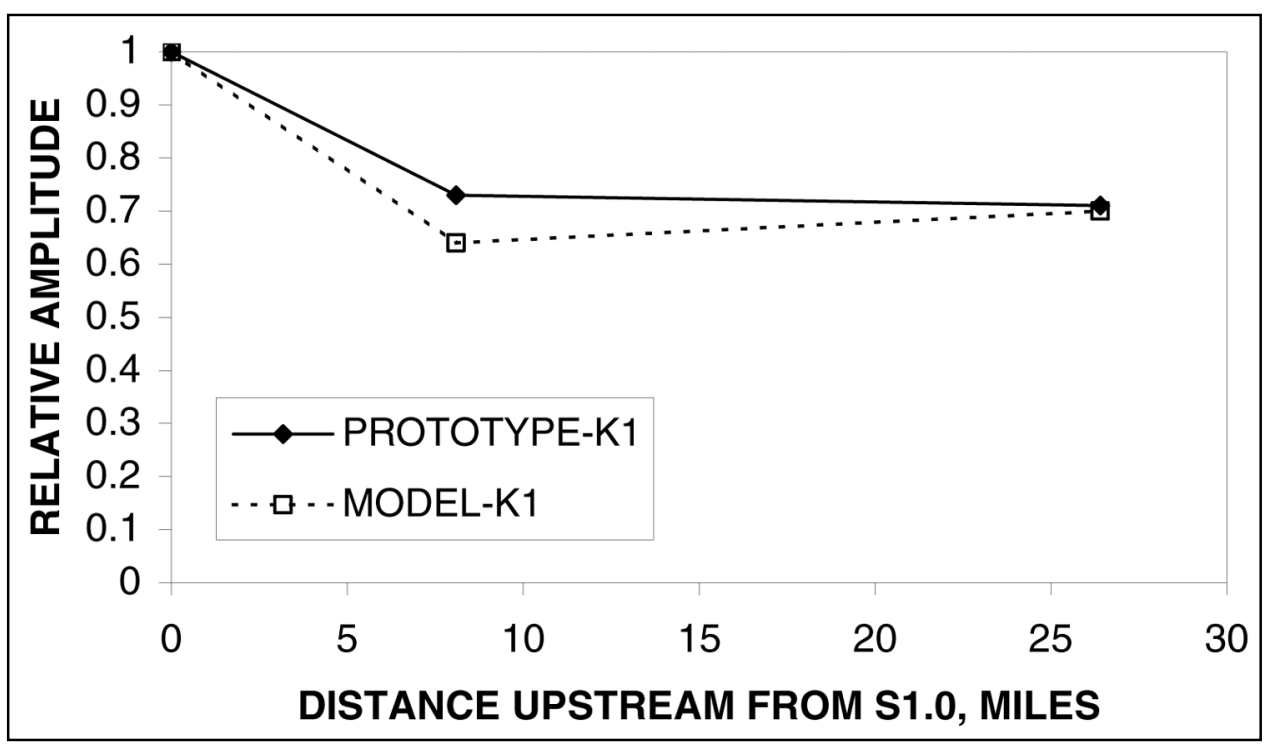

Figure 6. Prototype/model tidal amplitude comparison for $\mathrm{K} 1$ constituent

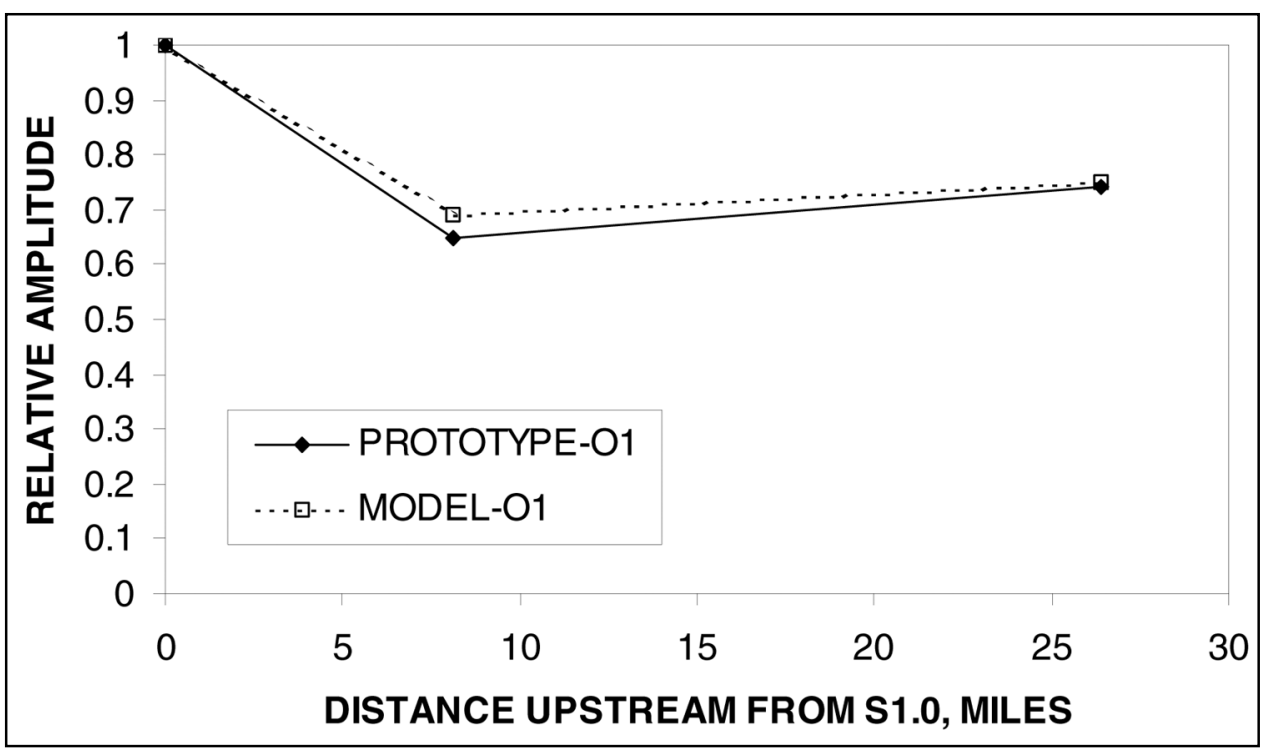

Figure 7. Prototype/model tidal amplitude comparison for $\mathrm{O} 1$ constituent

For a period of $23.93 \mathrm{hr}(\mathrm{K} 1)$, a significant reduction of the tidal range was evidenced from sta S1.0 to S3.0 (8.1 miles), about 27 percent. Upstream to sta S16.0 (26.4 miles), the tidal amplitude remained steady, increasing slightly by 2 percent. The model followed this trend remarkably well, separated from the prototype amplitude by only 12 percent at the most. Likewise, the reduction of the tidal range from sta S1.0 to S3.0 was about 35 percent for a $25.82 \mathrm{hr}$ period (O1), slightly larger than that of constituent K1. The tidal range then increased by 9 percent to sta S16.0. In this case, the model was even closer to the prototype amplitude, separated by only 5 percent at the most. 
Additionally, comparing the phase lag provided further insight about the model approximations. The phase lag is the difference between the phase at each station and that of sta S1.0. Figures 8 and 9 depict this information graphically.

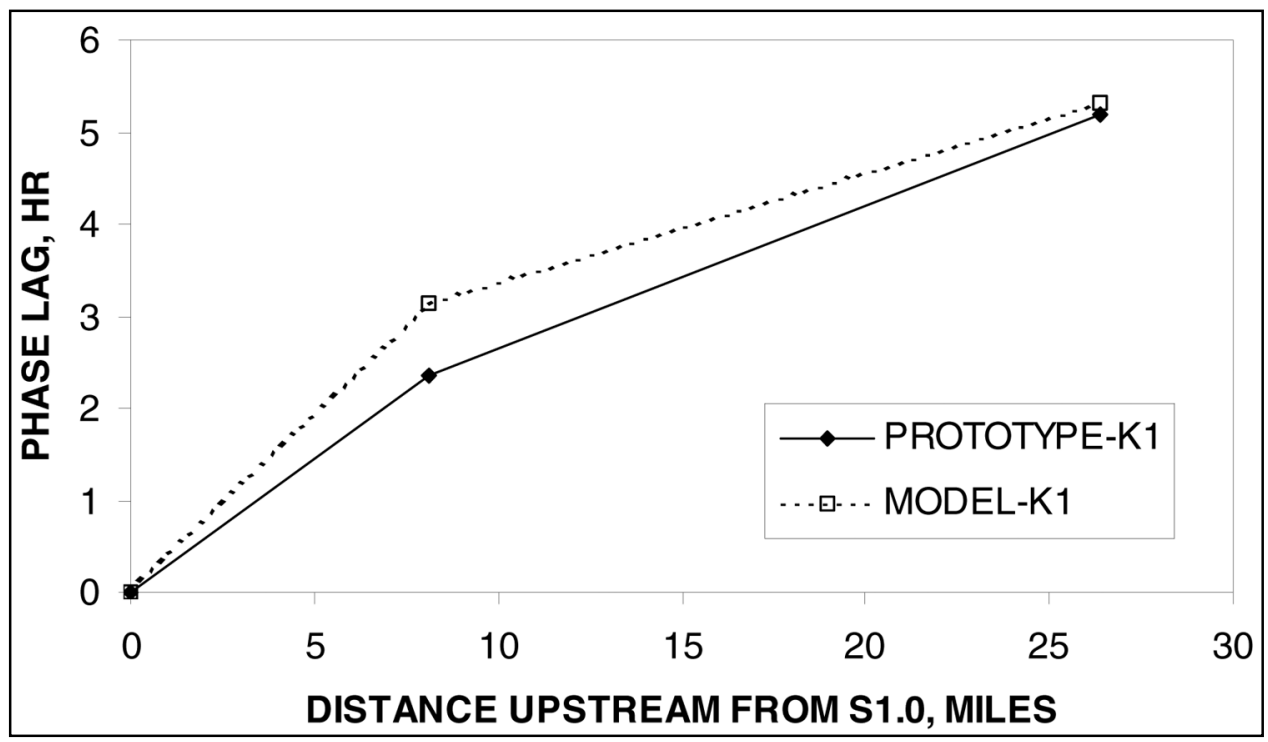

Figure 8. Comparison of prototype and model phase lag for $\mathrm{K} 1$ constituent

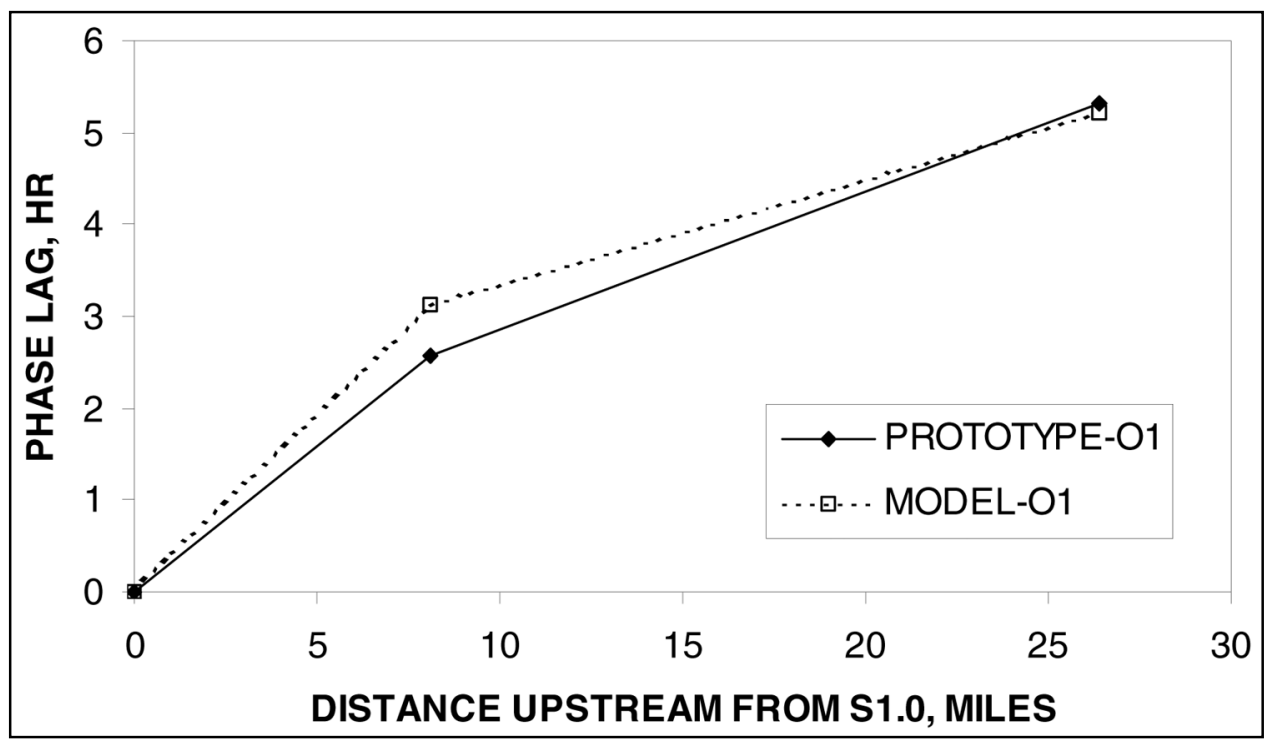

Figure 9. Comparison of prototype and model phase lag for $\mathrm{O} 1$ constituent

At sta S3.0, the prototype led the model by 47 min for constituent K1. Upstream at sta S16.0, the prototype led the model by much less, only around $7 \mathrm{~min}$. For constituent O1, the prototype led the model by about $33 \mathrm{~min}$, while at 26.4 miles upstream (S16.0), the model led the prototype by 6 min. 


\section{Salinity}

Plate 1 shows the modeled salinities versus the field data for three representative meter locations (sta 6.1, sta 12.1, and sta 14.0). These three stations are shown as a short check example to demonstrate that the model is functioning much as it did in the previous study. The period of time represented is 19 July 1990 to 15 January 1991. A high flow event occurred in the Trinity Basin in June, so the data include significant salinity variation as the system rebounded from near fresh conditions. The continuous meter readings from the field are shown as red lines. These meters were serviced periodically, at which time a single grab sample was taken. These are shown as an $\mathrm{X}$ for each recorded value. The model tracks the rebound in each case. For stas 12.1 and 14.0, the model underpredicts the salinity by about $3 \mathrm{ppt}$, whereas at sta 6.1 the rebound value of salinity is quite close.

\section{Conclusions}

The tidal and salinity results for the verification compared well to the previous study. The model thus remains calibrated and suitable for salinity and hydrodynamic studies of Galveston Bay, particularly base-plan type comparisons as performed in the current study. 


\section{Approach}

\section{Plans}

Since the completion of the channel deepening study, the actual deepening operation has been undertaken. The actual project has some differences from what was originally tested. This included the arrangement of the disposal islands as well as the actual depth dredged in the channel. For this reason, three configurations of the Houston Ship Channel through Galveston Bay were modeled. The tests were as follows:

a. "Final" - phase I as studied in the prior model study.

b. "Built" - phase I as built.

c. "Bargelanes" - phase I as built with the addition of the barge lanes.

The "Final" plan uses the phase I conditions as studied in the prior model investigation (Berger et al. 1995b), and has a $47-\mathrm{ft}-(45 \mathrm{ft}$ authorized plus $2 \mathrm{ft}$ of allowable overdepth) deep channel with a 530-ft width. The "Built" plan has a 47- to 49-ft deep channel as was actually dredged. The "Bargelanes" plan adds the barge lanes (14-ft depths extending $500 \mathrm{ft}$ from the center line of the navigation channel) to the "Built" plan.

The numerical model calculates water-surface elevations, current velocities (3-D components), and salinities at each node every $30 \mathrm{~min}$ for the 12-month period of simulation between January 1 and January 31 . Those data are processed to provide average monthly salinity contour plots for each plan for each of the 12 months (Plates 2-25). For comparison purposes, the "Built" and "Bargelanes" plans are plotted on the same graph.

\section{Computational Meshes}

Figures 10 through 12 illustrate the planform view of the computational meshes used. The grey areas denote the 3-D regions of the meshes. Table 1 shows the number of nodes and elements for each mesh. 


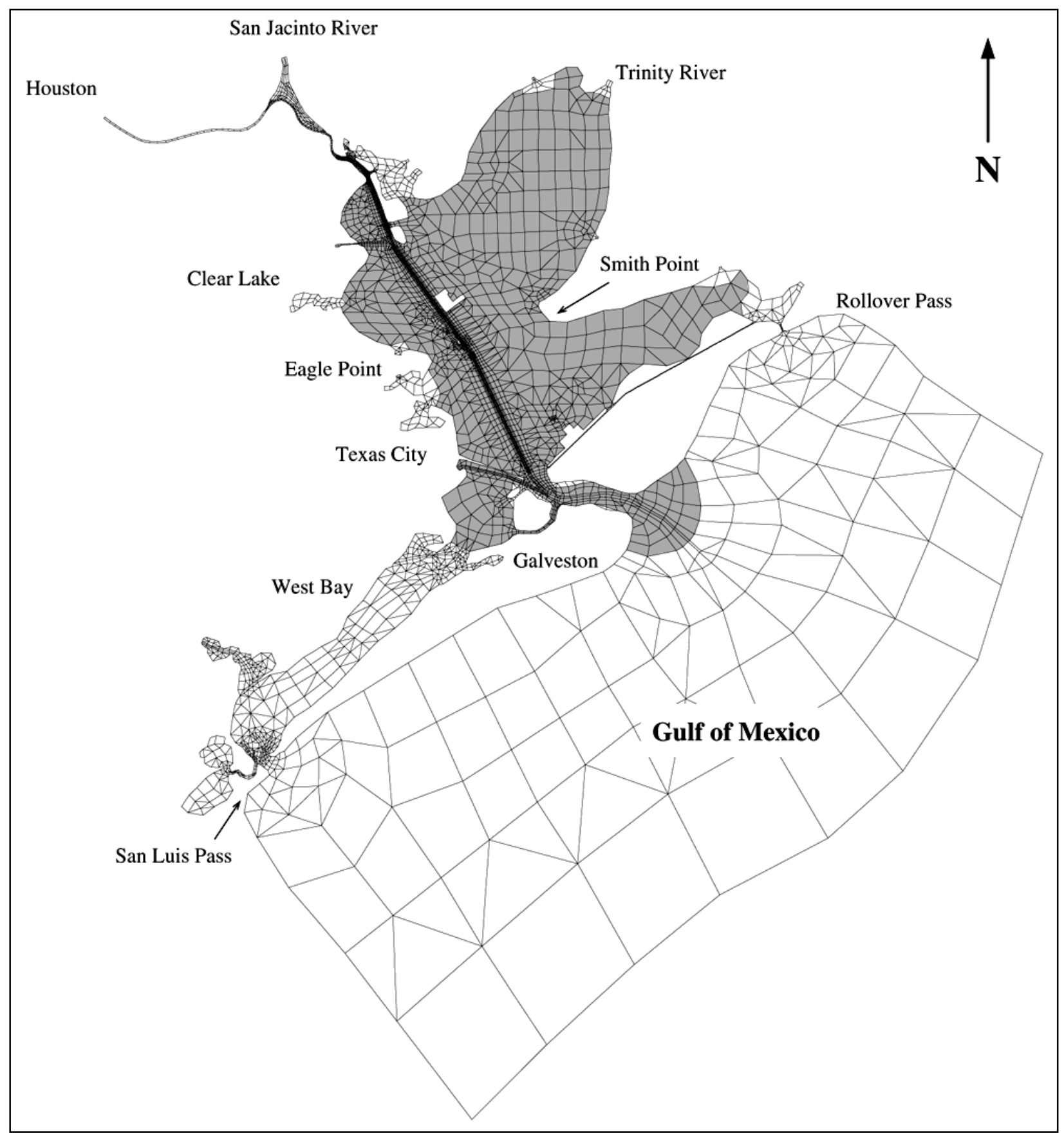

Figure 10. Computational mesh - phase I as studied in prior model study 


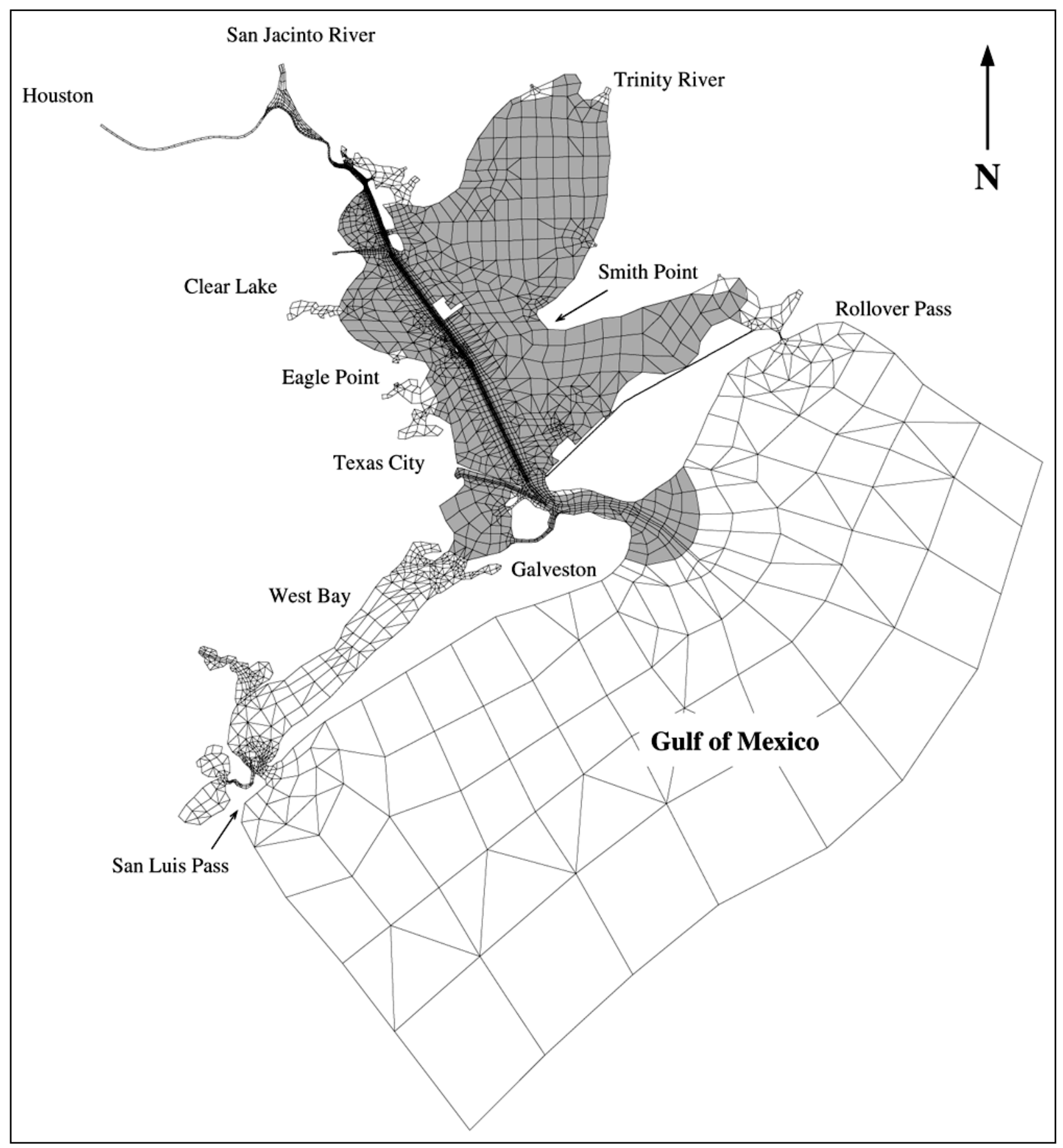

Figure 11. Computational mesh - phase I as built 


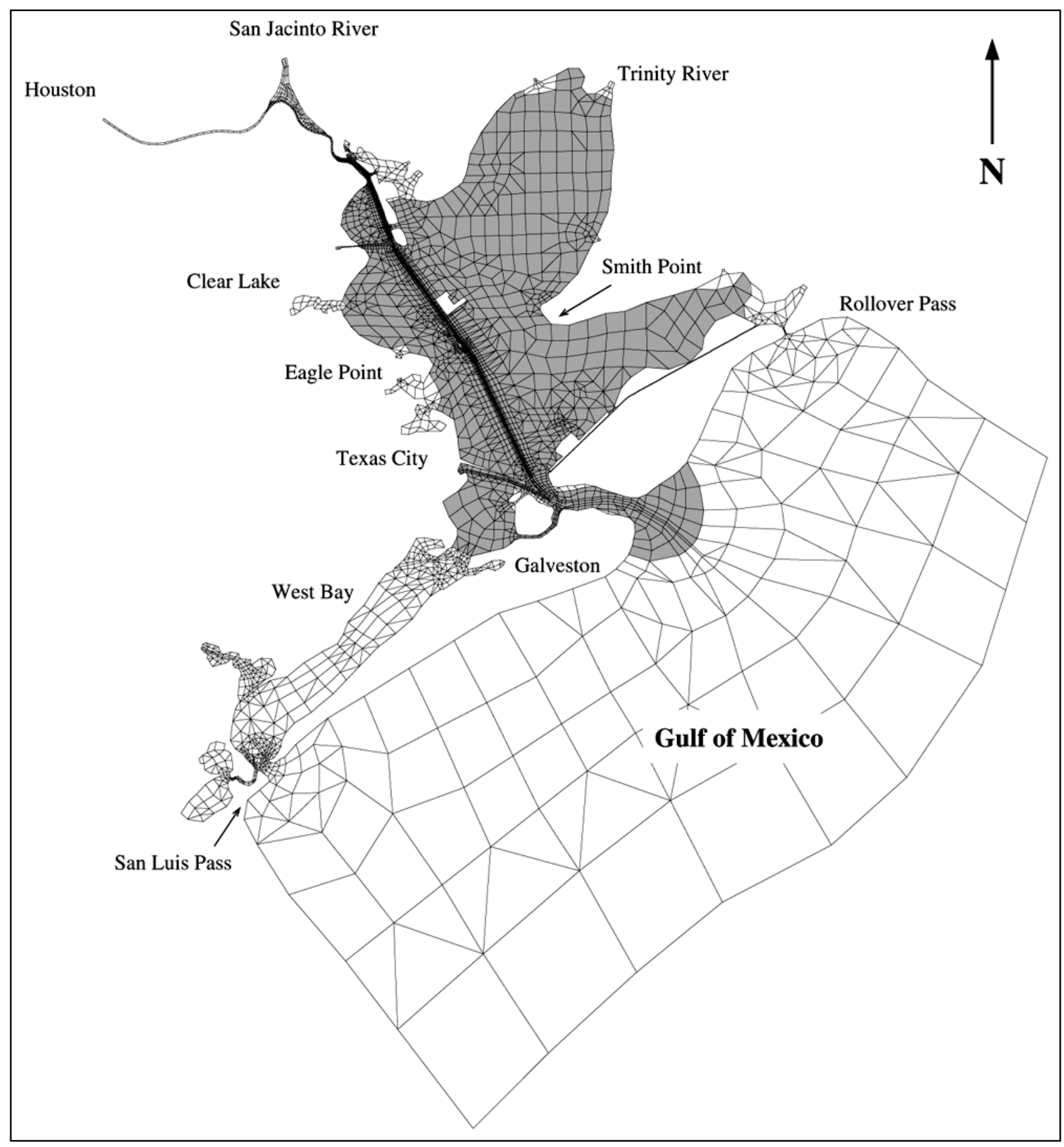

Figure 12. Computational mesh - phase I as built with addition of barge lanes

\begin{tabular}{|l|l|l|}
\hline $\begin{array}{l}\text { Table } 1 \\
\text { Mesh Sizes }\end{array}$ \\
\hline \hline Mesh & Nodes & Elements \\
\hline Phase I as studied prior & 12,615 & 4,380 \\
\hline Phase I as built & 12,613 & 4,386 \\
\hline Phase I as built with barge lanes & 12,614 & 4,387 \\
\hline
\end{tabular}




\section{Experimental Conditions}

Since most of this work is based on prior investigations, only a brief discussion of the specifics of the experimental conditions are addressed in the following sections. For a more detailed discussion see Berger et al. 1995b.

\section{Inflows}

Modeling conditions for the plan experiments use the "Present" low-flow hydrologic era from the prior investigation. The low-flow scenario was chosen since it is regarded as the most critical.

In addition to the river inflows, two Reliant Energy electric power generation plants were included in the model: the Cedar Bayou and Robinson plants. Monthly intake rates for the year 1990 were used for all testing. Salinity values obtained at the intake are used as the boundary condition at the discharge.

\section{Tides}

The tidal boundary data were from NOS/NOAA sta 877-1510 at Pleasure Pier for calendar year 1984, which was found to be a typical temperature year. The model boundary, which is about 26 miles offshore, used these data shifted forward in time by $1.31 \mathrm{hr}$. This matched the phase at Pleasure Pier. Periods of less than $3 \mathrm{hr}$ were removed by filtering, preventing noise in the results.

\section{Wind}

Wind data for 1984 were obtained from the National Weather Service for Houston Intercontinental Airport. From a correlation with data collected at sta S10.1 in Galveston Bay during the verification period, these wind data were transposed to the bay system.

\section{Salinity}

Gulf boundary salinities are based on 15-year monthly averages for the Gulf, and the work of Conchrane and Kelly (1986). The final salinity field results from the verification run are used as the initial conditions for each of the plan experiments. 


\section{Results}

\section{Phase I Final (Plates 2-13)}

This is the bathymetry and disposal configuration that matches that previously tested in the Houston-Galveston Ship Channel Deepening Study (Berger et al. 1995b). The plates represent the bottom salinity concentrations. Beginning in January the isohalines generally show increasing intrusion along the channel until April. The freshwater inflow reaches its peak in April and May and the salinity recedes a bit. The impact of the Bayport Ship Channel is sometimes evident in the shape of the contours at certain times, such as February, May, and June. June appears to be the minimum month-average salinity. The intrusion increases as the fresh water is reduced throughout the summer and fall months. The peak intrusion is in October and November.

\section{Phase I as Built and Phase I as Built with Barge Lanes (Plates 14-25)}

Generally the intrusion follows the same pattern as that found in "Phase I Final." The minimum intrusion is in June and the maximum is in October. The barge lanes are $14 \mathrm{ft}$ deep at mlw. The southern reach of the bay below Eagle Point is deeper than this and so no deepening takes place there. Above Eagle Point the barge lanes must be dredged. The most noticeable differences between the conditions with and without the barge lanes occurs in October, November, and December. As with the channel deepening the primary area of influence is the upper western portion of the bay from Clear Lake and above. The isohalines are also shifted upstream in Trinity Bay in October and November. This is partially due to the increased salinity at the intake of the Reliant Energy electric generation plant at Cedar Bayou, that has its discharge in the upper (northern) Trinity Bay, and to greater intrusion along the Houston Ship Channel. 


\begin{tabular}{|c|c|c|c|c|c|c|c|c|c|c|c|c|c|}
\hline \multirow{2}{*}{\multicolumn{2}{|c|}{\begin{tabular}{|l|} 
Table 2 \\
Modeled Month \\
Lanes, for Selec \\
\end{tabular}}} & & & & & & & & & & & & \\
\hline & & Jan. & Feb. & Mar. & Apr. & May & June & July & Aug. & Sept. & Oct. & Nov. & Dec. \\
\hline \multirow{2}{*}{ Location 1} & Built & 15.8 & 13.8 & 15.2 & 15.4 & 13.6 & 14.2 & 15.8 & 18.3 & 19.7 & 19.8 & 19.3 & 17.7 \\
\hline & Barge & 15.8 & 13.7 & 14.0 & 15.8 & 14.3 & 14.3 & 16.5 & 18.7 & 20.1 & 20.7 & 20.4 & 18.7 \\
\hline \multirow{2}{*}{ Location 2} & Built & 10.9 & 9.0 & 10.8 & 10.8 & 9.7 & 10.6 & 12.6 & 14.7 & 15.4 & 16.3 & 15.4 & 12.5 \\
\hline & Barge & 11.0 & 8.8 & 10.2 & 11.3 & 10.3 & 10.7 & 12.9 & 14.8 & 15.8 & 17.1 & 16.1 & 13.5 \\
\hline \multirow{2}{*}{ Location 3} & Built & 8.6 & 7.3 & 7.1 & 7.1 & 5.7 & 6.8 & 9.4 & 12.4 & 12.9 & 14.0 & 14.1 & 10.3 \\
\hline & Barge & 8.5 & 8.1 & 7.0 & 7.8 & 6.6 & 7.5 & 9.4 & 11.7 & 13.4 & 15.1 & 14.8 & 10.9 \\
\hline \multirow{2}{*}{ Location 4} & Built & 12.2 & 10.6 & 10.3 & 10.9 & 9.3 & 9.8 & 11.5 & 14.2 & 15.8 & 16.6 & 16.5 & 14.9 \\
\hline & Barge & 12.1 & 10.8 & 10.4 & 10.6 & 10.2 & 10.5 & 11.6 & 14.3 & 16.0 & $\begin{array}{l}17.3 \\
\end{array}$ & 17.6 & 15.3 \\
\hline
\end{tabular}

The isohalines shown in the plates are contours of equal concentration. These are good for getting overall salinity distributions and shifts in salinity patterns, but can be difficult in determining salinity at locations. Table 2 shows the actual mean monthly values of salinity at four locations for all months and for "Phase I as Built" and "Phase I as Built with Barge Lanes." These four locations are identified in Figure 13. Locations 1 and 2 are about the same distance up the navigation channel, with location 1 west of the channel and location 2 east. Location 2 is close to the intake of Reliant Energy's Cedar Bayou Electric Generating Station. Location 3 is further up Trinity Bay closer to the discharge from the power station. Location 4 is in the middle of Trinity Bay and should be useful in determining any additional intrusion directly from Houston Ship Channel with the proposed barge lanes. 


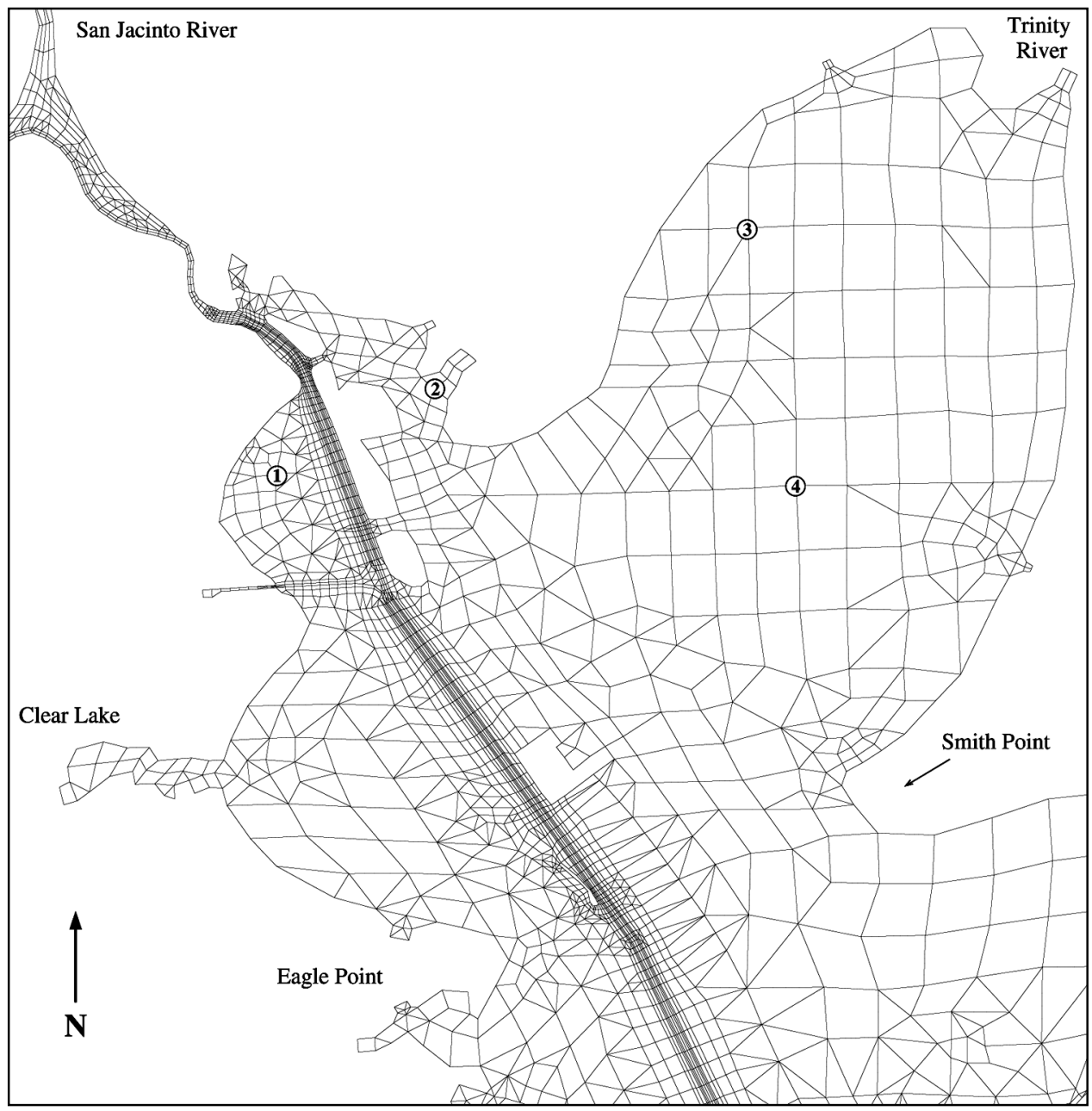

Figure 13. Select grid locations for comparison of phase I as built and phase I as built with barge lanes

First considering location 4, the maximum increase in month-average salinity due to the barge lanes is $1.1 \mathrm{ppt}$ in November. Location 1 shows decrease in salinity due to the barge lanes in the early spring, but by November it also shows a $1.1 \mathrm{ppt}$ increase in salinity due to the barge lanes. Location 2 shows a slight decrease in salinity in early spring $(0.6 \mathrm{ppt})$ and a maximum increase of $1.0 \mathrm{ppt}$ in December. Location 3 should reflect the influence of the outflow from the power plant as well as the direct change in the salinity from the navigation channel (as indicated by location 4). The maximum increase in salinity is $1.1 \mathrm{ppt}$ in October. This is closer to the timing of the increase at location 4, which may suggest that the direct intrusion up Trinity Bay is more influential than the power plant. However, the plates of isohalines sometimes show the distinctive flow of salt water into upper Trinity Bay from the power plant (see Plate 23).

The average change in salinity is $+0.4,+0.3,+0.4$ and $+0.4 \mathrm{ppt}$ for locations $1,2,3$, and 4 respectively. The most noteworthy increases are late in the year just after the peak salinity period. To get an idea on the relative magnitude of this change, we will compare these results to that caused by the river inflows to the bay. From Berger et al. 1995a, a salinity change of about $1.0 \mathrm{ppt}$ in upper Trinity Bay can be developed from a 10 percent change in freshwater inflow. These 0.4 ppt increases in salinity on average have roughly the impact of a 4 percent reduction in freshwater inflow. 


\section{Summary and Conclusions}

The basic goal of this modeling effort is to evaluate the impact of the addition of barge lanes on each side of the Houston Ship Channel through Galveston Bay. The parameter of concern is salinity. The following steps were taken to perform this evaluation:

a. The previously developed RMA10-WES 3D hydrodynamic and salinity model used to evaluate the Houston-Galveston Ship Channel deepening would be activated and upgraded to the present version of RMA10-WES called TABS-MDS.

$b$. The mesh was refined along the channel to more accurately represent the region in which the barge lanes would be added.

c. The model was run through a verification check, by using the 1990 bathymetric conditions and running the wind, freshwater inflow and tide conditions used for the prior model verification.

d. All testing after verification was conducted for what are believed to be critical conditions. This is the hydrologic scenario termed 1990 low flow.

$e$. A single yearlong run was made of what is called the "Phase I Final" condition. This is the bathymetry and disposal island configuration that was run as the final condition in the prior channel deepening study. The channel dimensions were $47 \mathrm{ft} \mathrm{mlw}$ by $530 \mathrm{ft}$ wide. These results are to be used to make sure that the results are similar to that given during the previous study.

f. Two runs were then made over the same yearlong period. These were the "Phase I as Built" and the "Phase I as Built with Barge Lanes Condition." The main navigation channel dimensions were $530 \mathrm{ft}$ wide, but the depth was 47 to $49 \mathrm{ft}$ deep at mlw in the lower bay. The upper bay and the bayou section had a depth of $47 \mathrm{ft} \mathrm{mlw}$. The barge lane depth was $14 \mathrm{ft}$ mlw. These runs are the basis of the salinity evaluation of the barge lanes.

The model tide and salinity verification check showed that the present model is performing with precision similar to that of the prior study. The "Phase I Final" 
test showed that the present model predicts a salinity regimen much like that of the previous study.

The addition of the barge lanes had little impact on the lower (southern) portion of Galveston Bay. The upper region of Galveston Bay and Trinity Bay on average showed about a $0.4 \mathrm{ppt}$ increase. In these same upper regions the spring period, in which the salinity rebounds, showed a drop in salinity compared to the same channel configuration without the barge lanes.

The addition of the barge lanes tended to raise the salinity in the upper western portion of Galveston Bay and in Trinity Bay in late fall (October, November, and December). This Trinity Bay increase appears to be due to the increased intrusion directly from the navigation channel up Trinity Bay, as well as the transfer of increased salinity at the intake of the Reliant Energy's Cedar Bayou Electric Generation station. This plant has an intake near Cedar Bayou, which is relatively near the navigation channel but has a discharge in upper Trinity Bay. The change in salinity at the intake in turn changes the salinity discharged into Trinity Bay. 


\section{References}

Berger, R. C., McAdory, R. T., Martin, W. D., Schmidt, J. H. (1995a). "HoustonGalveston Navigation Channels, Texas Project; Report 3: Three-dimensional hydrodynamic model verification," Technical Report HL-92-7, U.S. Army Engineer Waterways Experiment Station, Vicksburg, MS.

Berger, R. C., McAdory, R. T., Schmidt, J. H., Martin, W. D., and Hauck, L. M. (1995b). "Houston-Galveston Navigation Channels, Texas Project; Report 4: Three-dimensional numerical modeling of hydrodynamics and salinity," Technical Report HL-92-7, U.S. Army Engineer Waterways Experiment Station, Vicksburg, MS.

Cochrane, J. D., and Kelly, F. J. (1986). "Low-frequency circulation on the Texas-Louisiana continental shelf," Journal of Geophysical Research 91(C9), 10645-10659.

Fagerburg, T. L., Fisackerly, G. M., Parman, J. W., and Coleman, C. J. (1994). "Houston-Galveston Navigation Channels, Texas Project, Report 1, Galveston Bay field investigation," Technical Report HL-92-7, U.S. Army Engineer Waterways Experiment Station, Vicksburg, MS.

Henderson-Sellers, B. (1984). "A simple formula for vertical eddy diffusion coefficients under conditions of nonneutral stability," Journal of Geophysical Research 87(C8), 5860-5864.

King, I. P. (1982). "A finite element model for three dimensional flow," Resource Management Associates, Lafayette, CA, for U.S. Army Engineer Waterways Experiment Station, Vicksburg, MS.

. (1985). "Strategies for finite element modeling of three dimensional hydrodynamic systems," Advances in Water Resources 8, 69-76.

. (1993). "RMA-10, a finite element model for three dimensional density stratified flow," Department of Civil and Environmental Engineering, University of California, Davis.

Mellor, G. L., and Yamada, T. (1982). "Development of a turbulence closure model for geophysical fluid problems," Reviews of Geophysics and Space Physics 20(4), 851-875. 
Pritchard, D. W. (1982). "A summary concerning the newly adopted Practical Salinity Scale, 1978, and the International Equation of State of Seawater, 1980," Marine Sciences Research Center, State University of New York, Stony Brook, NY.

Stelling, G. S., and van Kester, J. A. T. M. (1993). "Horizontal gradients in sigma transformed bathymetries with steep bottom slopes," Hydraulic Engineering '93, Proceedings of the 1993 Conference, American Society of Civil Engineers, 2123-2134.

Wu, J. (1980). "Wind-stress coefficients over sea surface near neutral conditions-a revisit," Journal of Physical Oceanography 10(5), 727-740. 


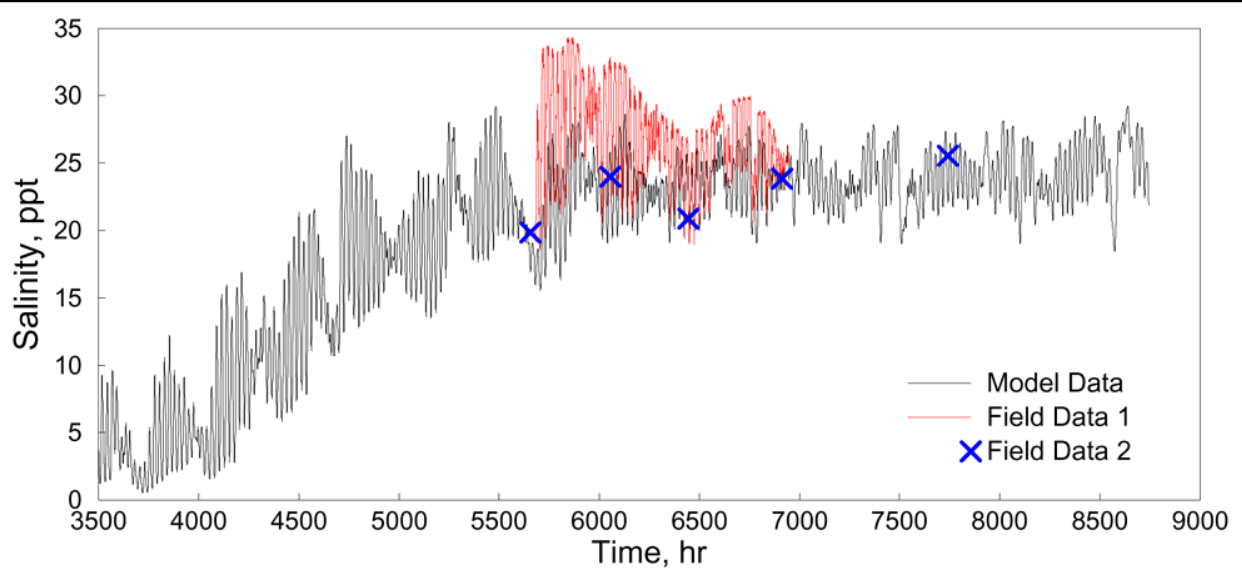

Station 6.1

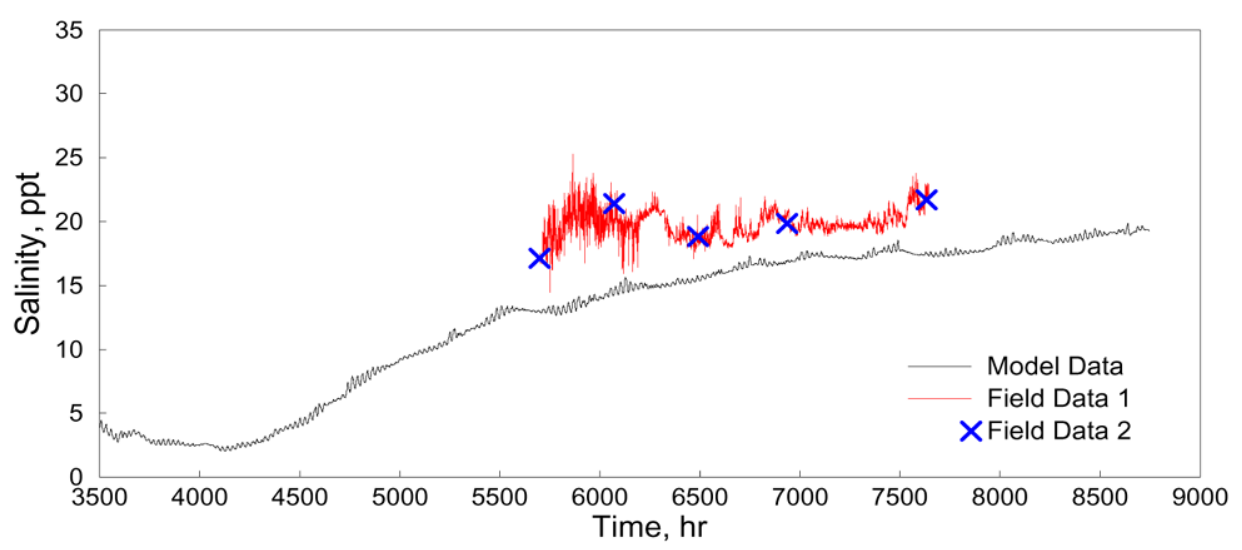

Station 12.1

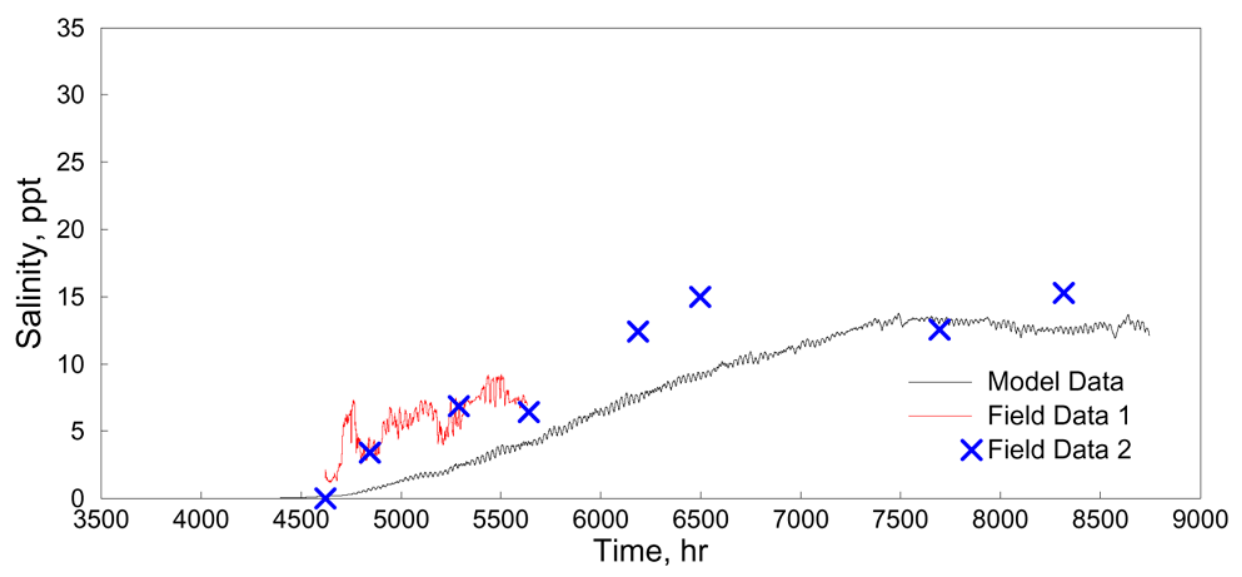

Station 14.0

Galveston Bay Salinities

Model Verification

Stations 6.1, 12.1, 14.0 


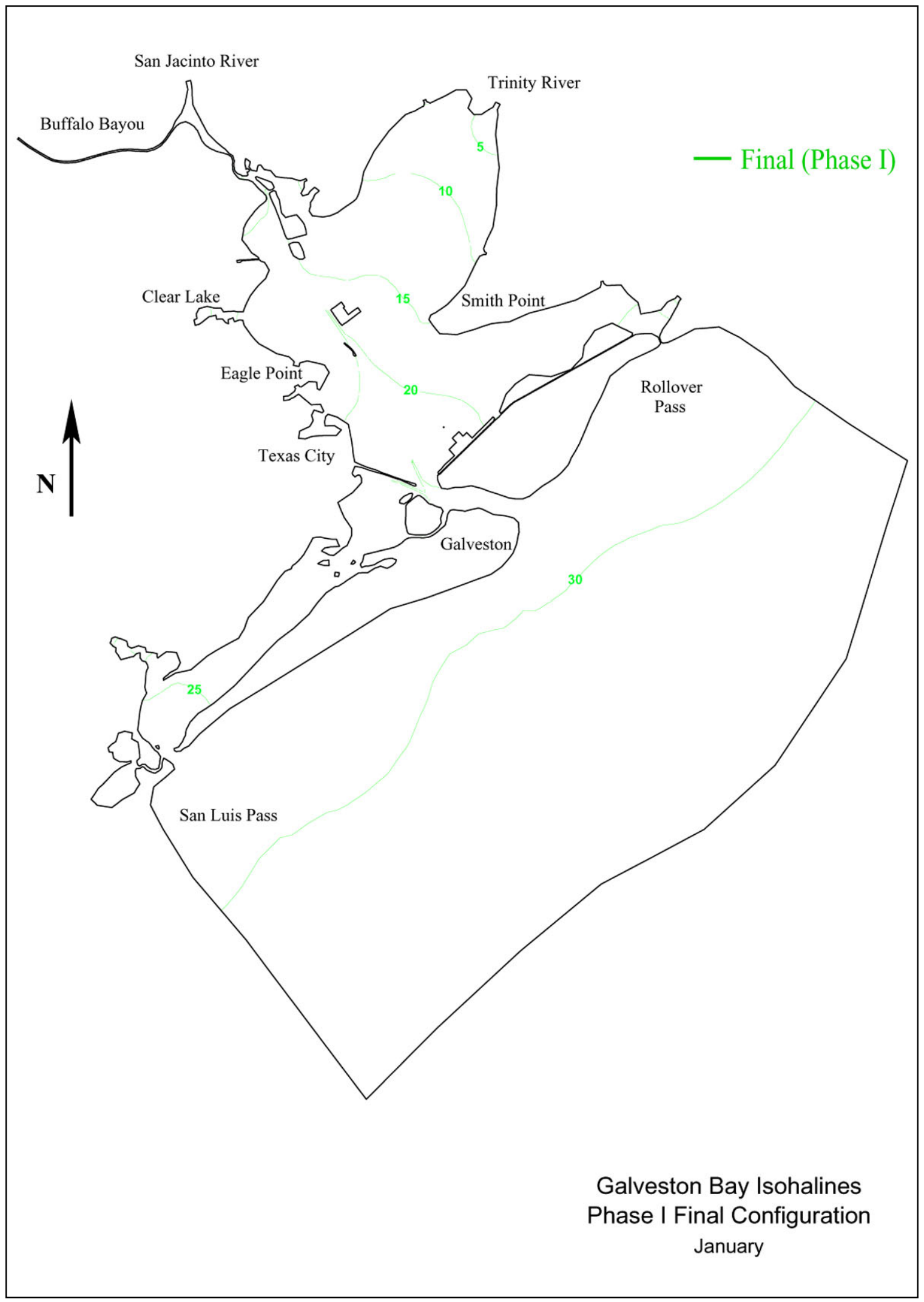

Plate 2 


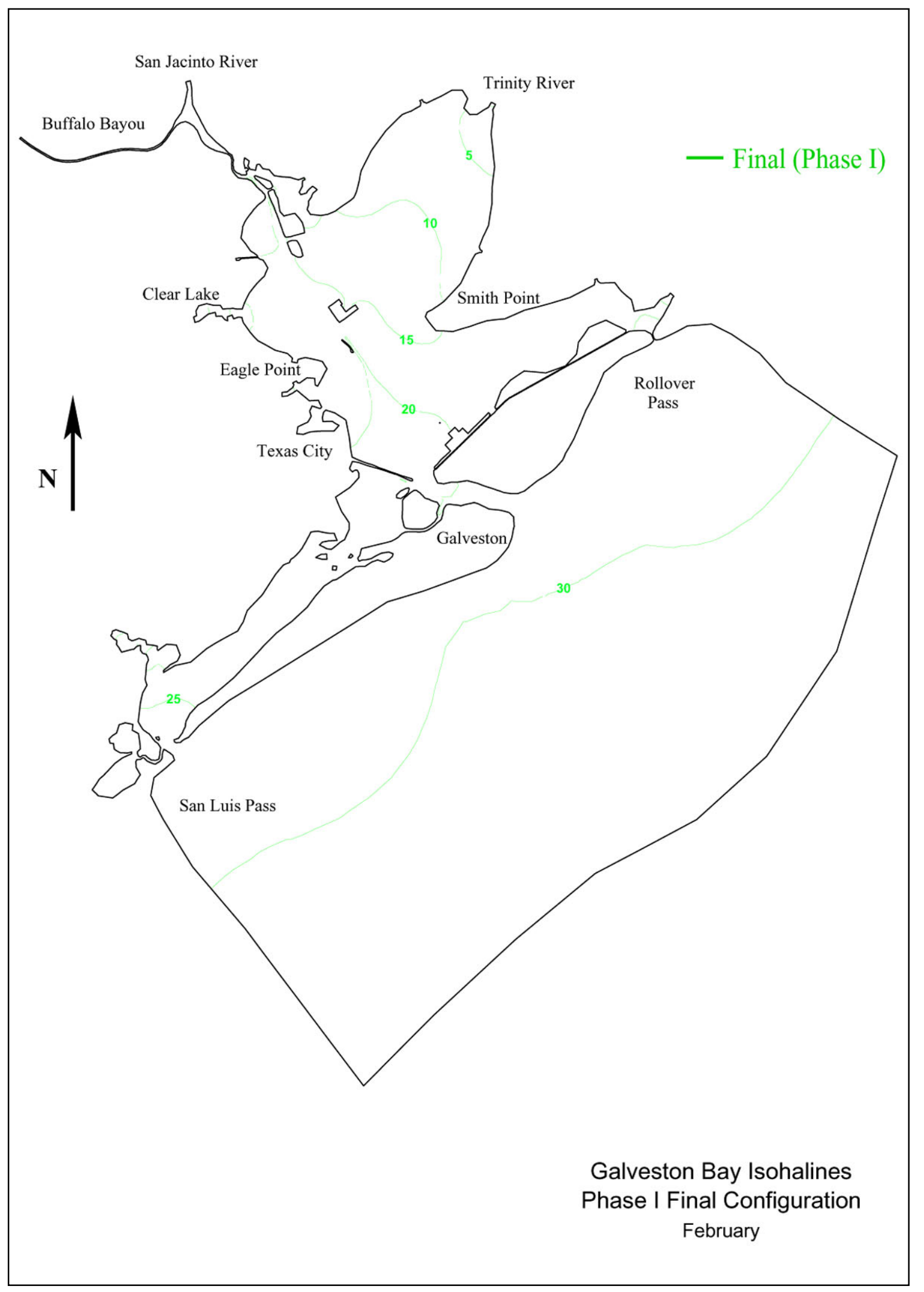

Plate 3 


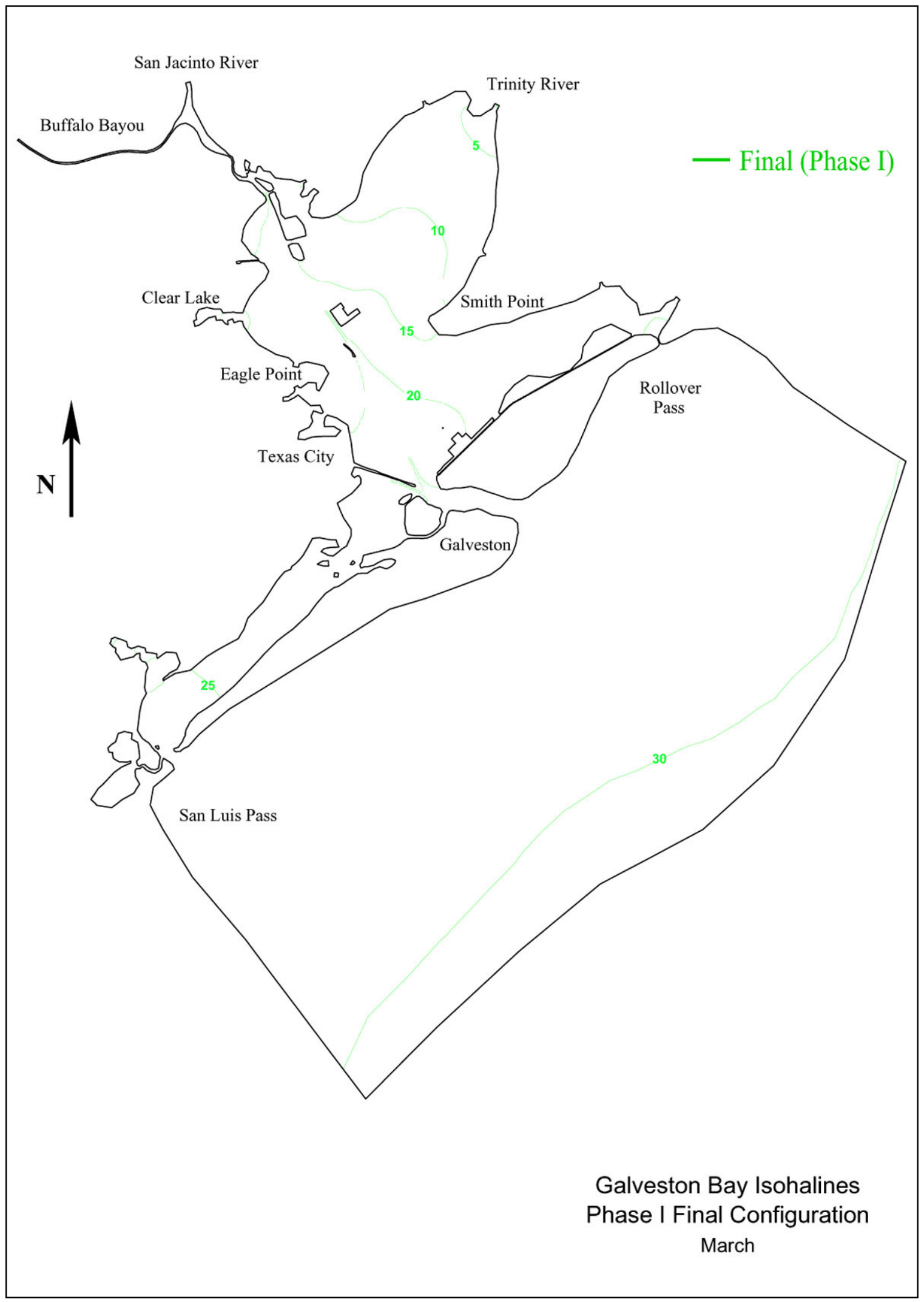

Plate 4 


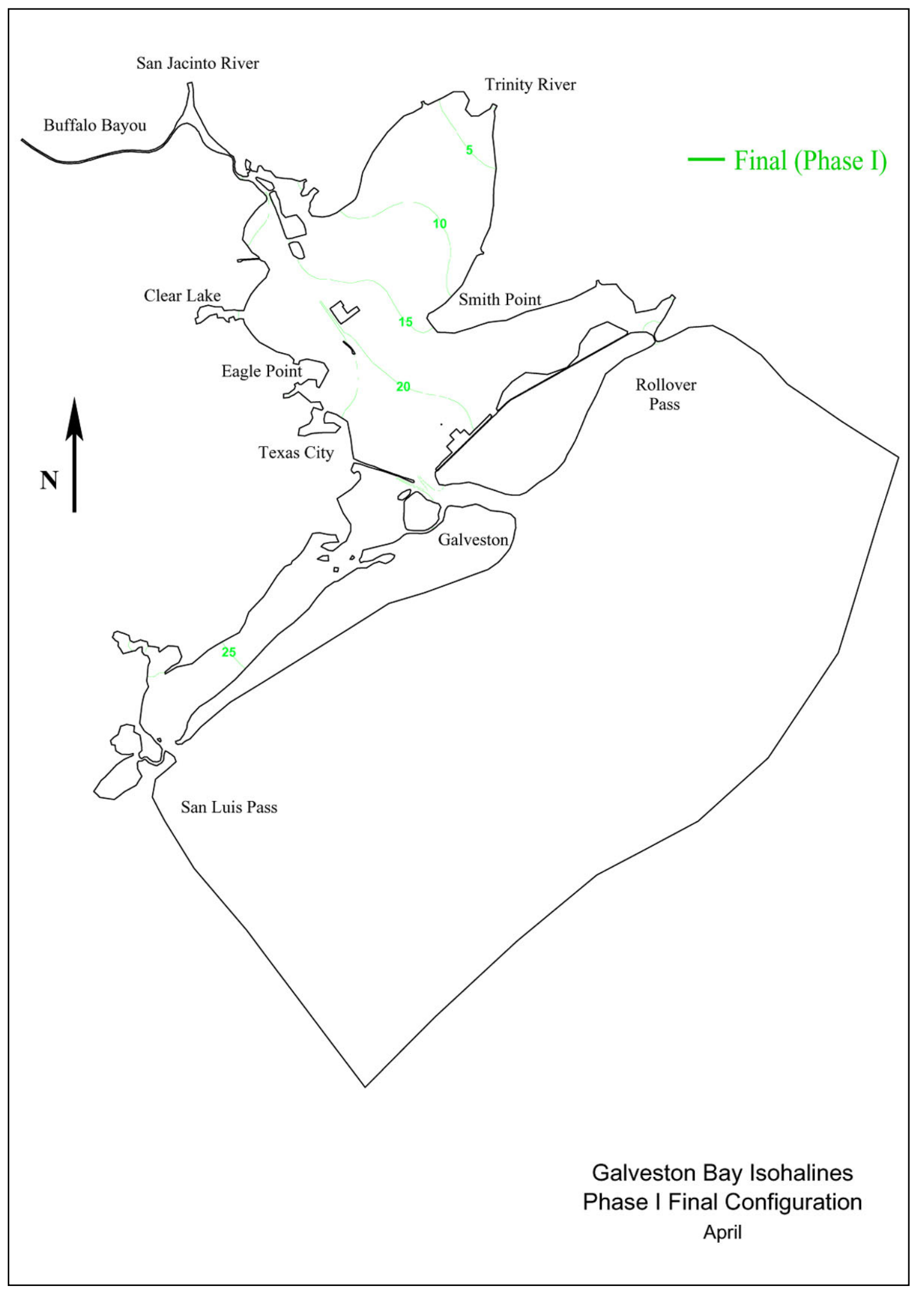

Plate 5 


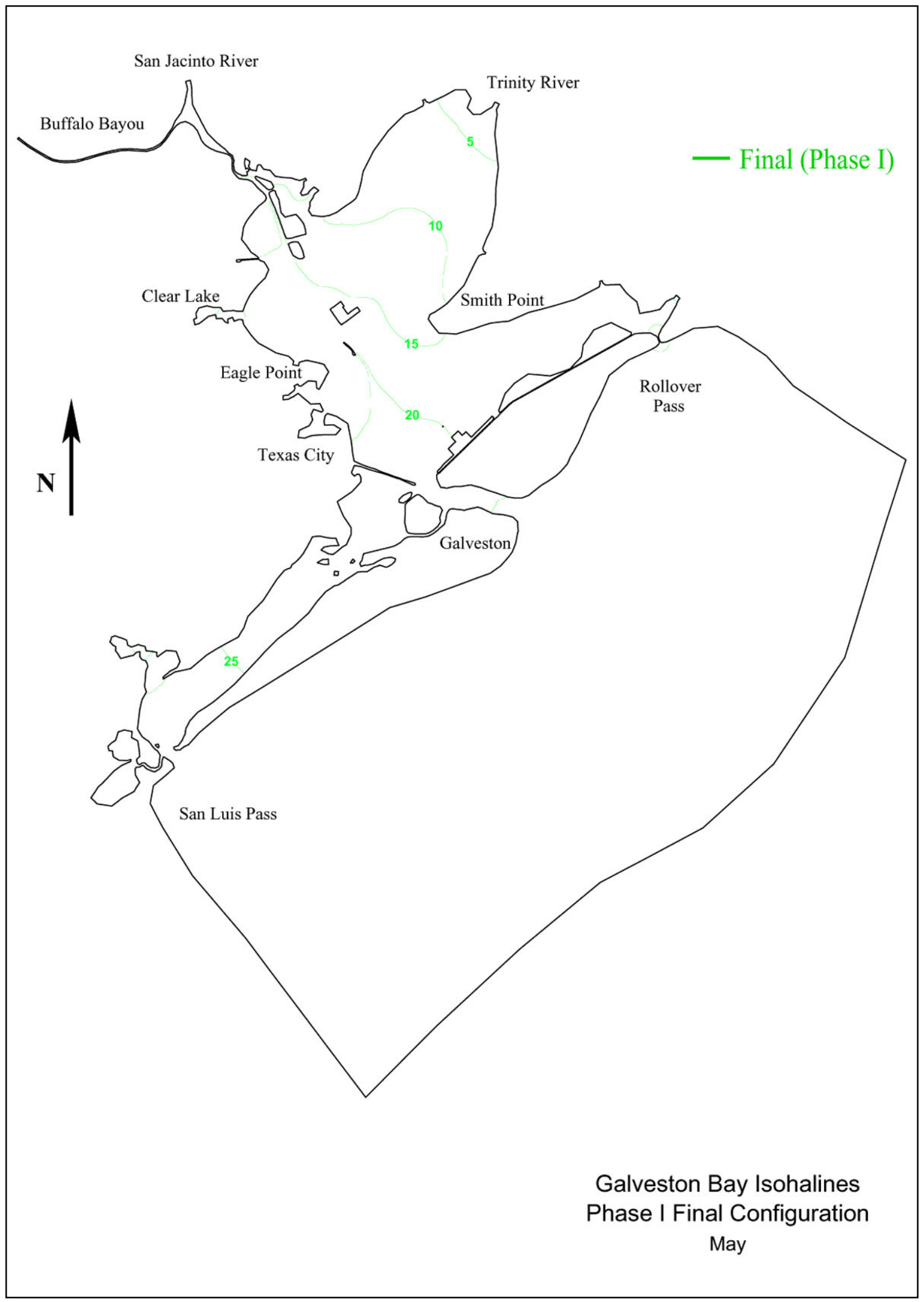

Plate 6 


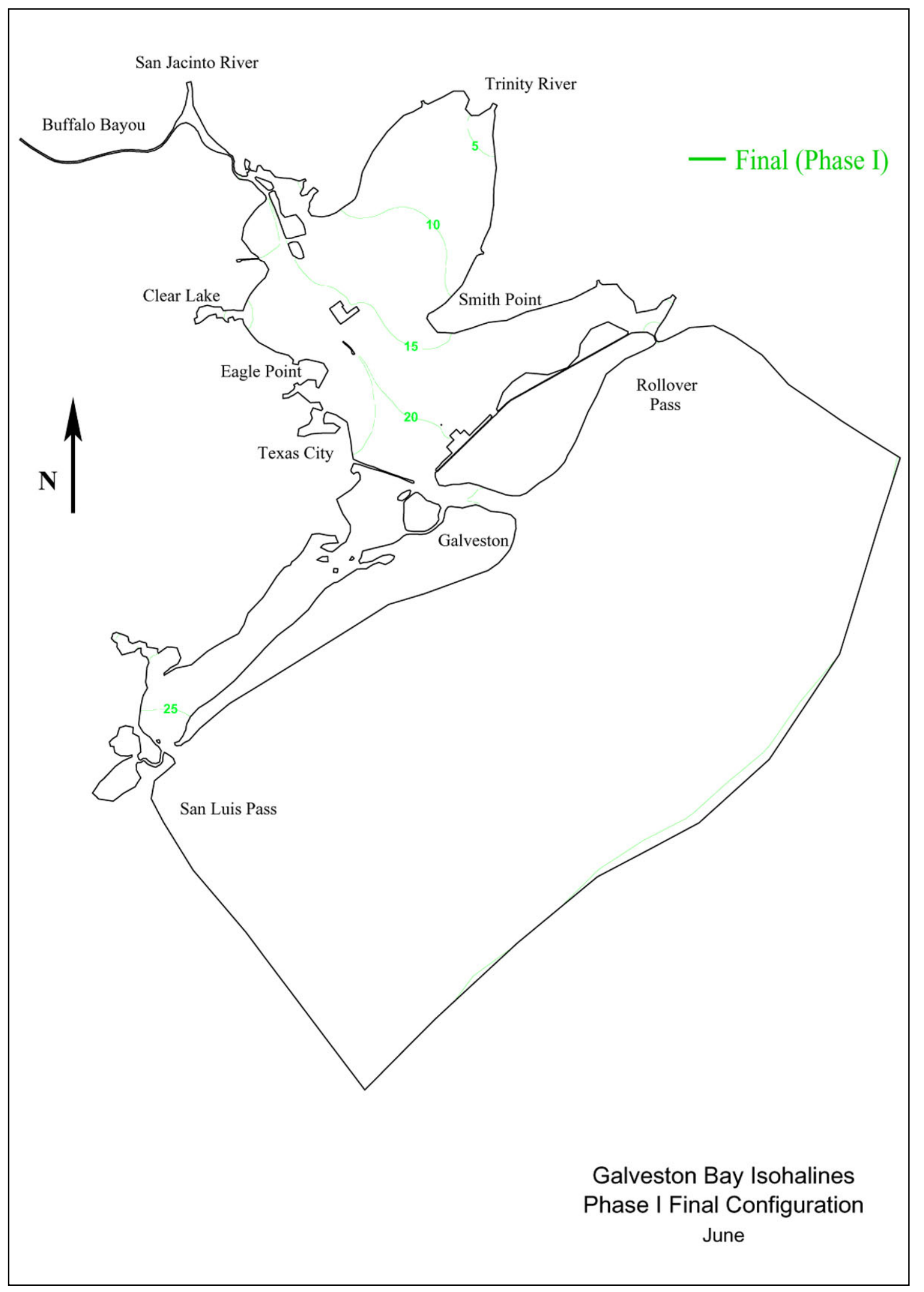

Plate 7 


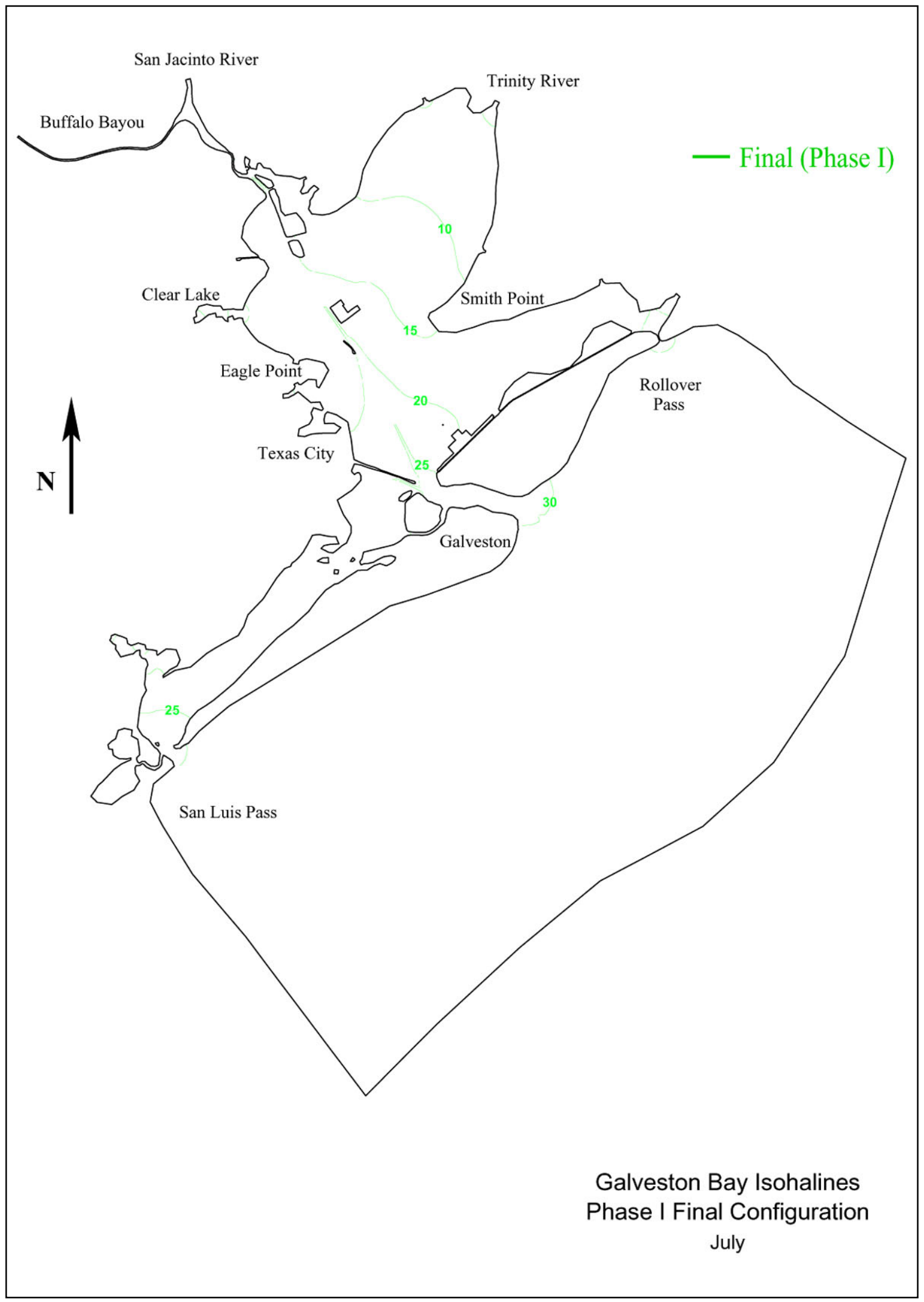

Plate 8 


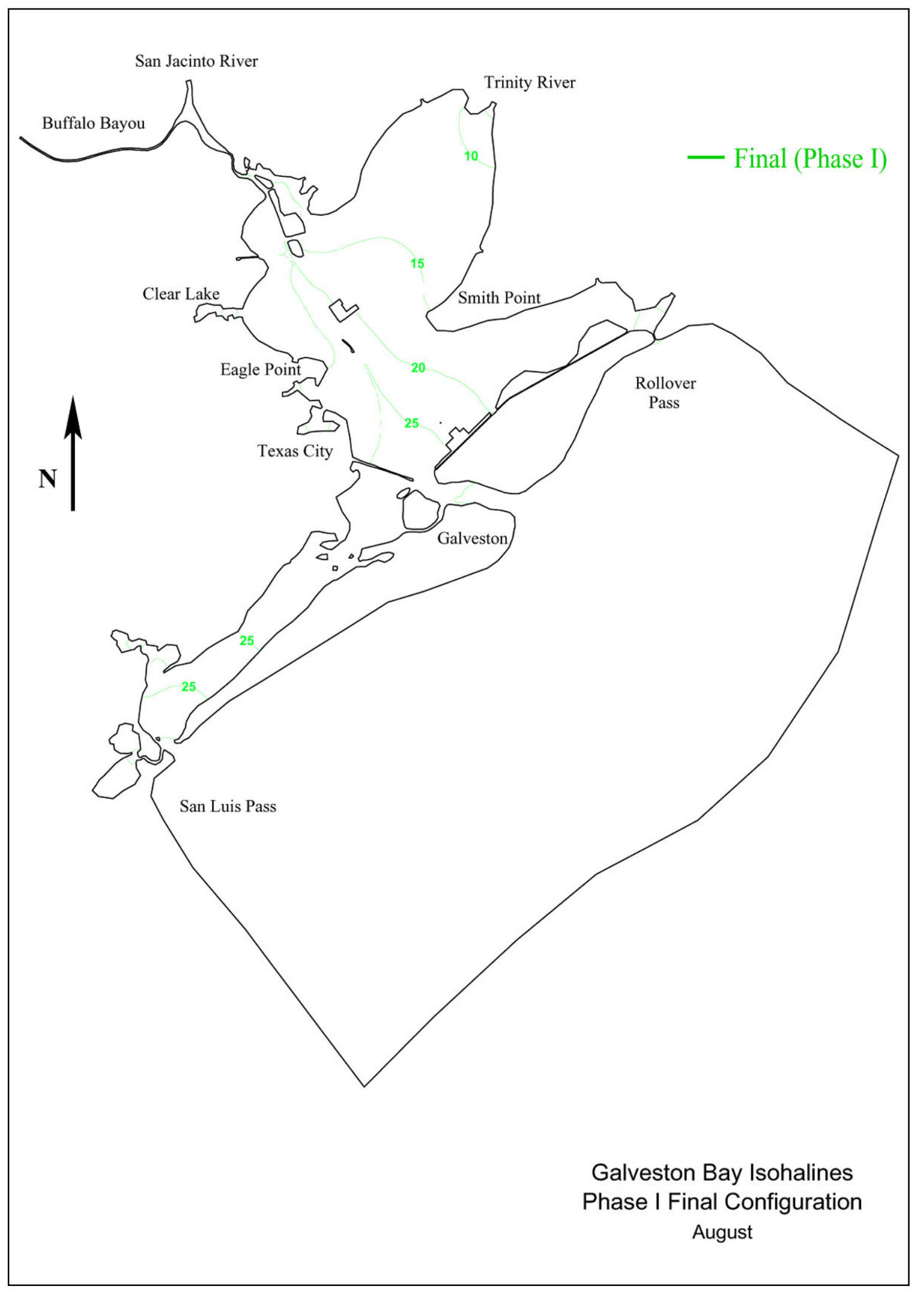

Plate 9 


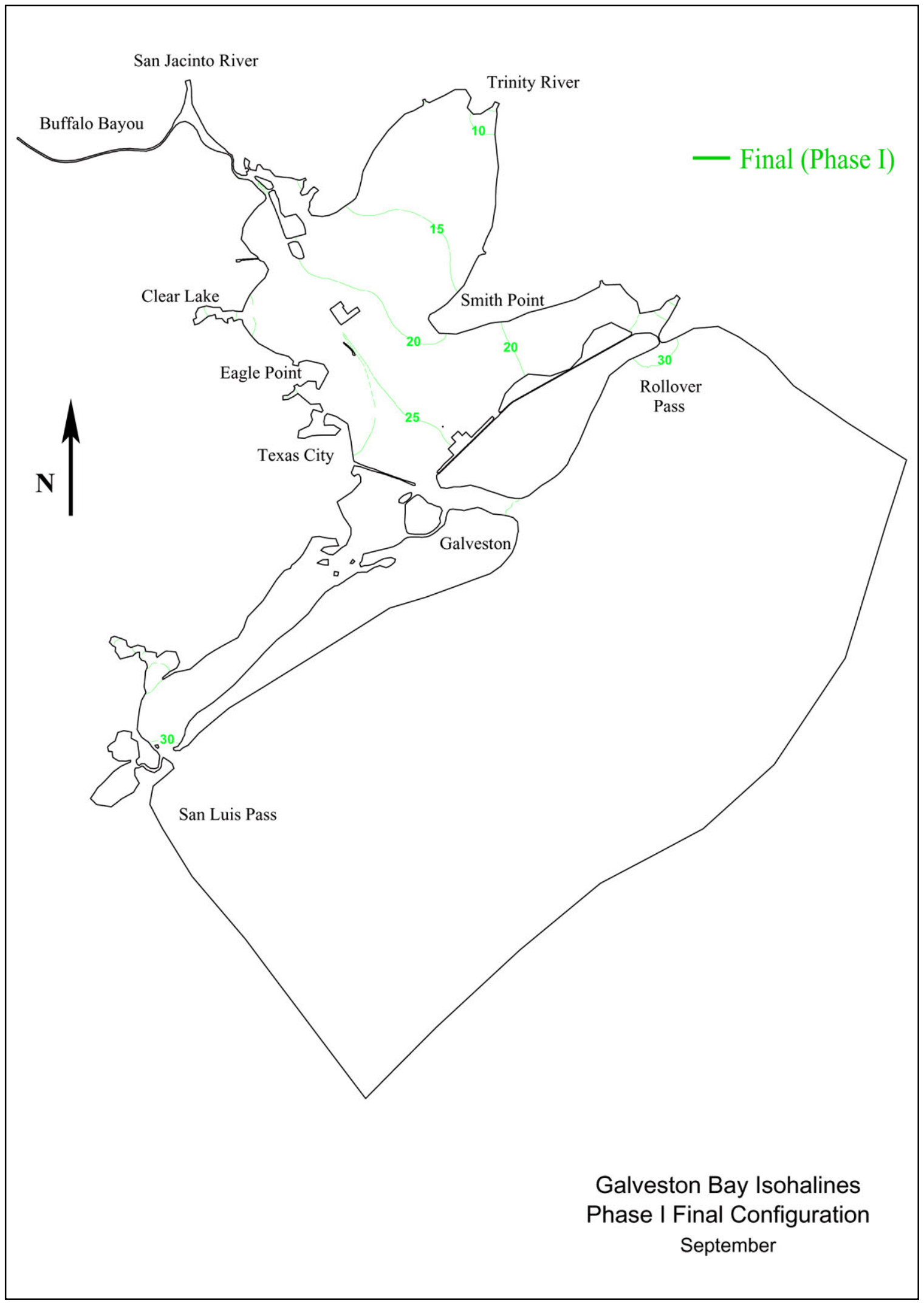

Plate 10 


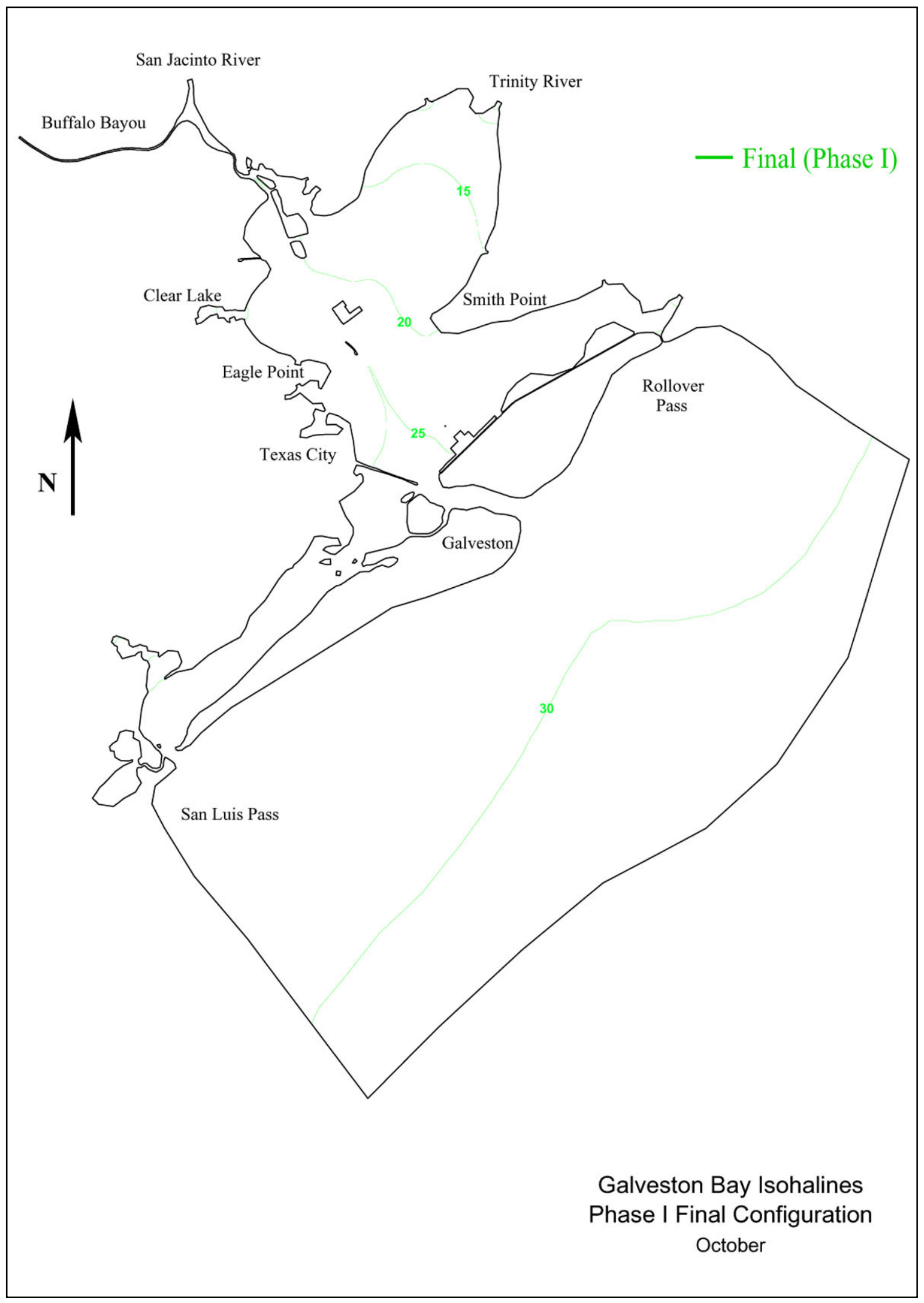

Plate 11 


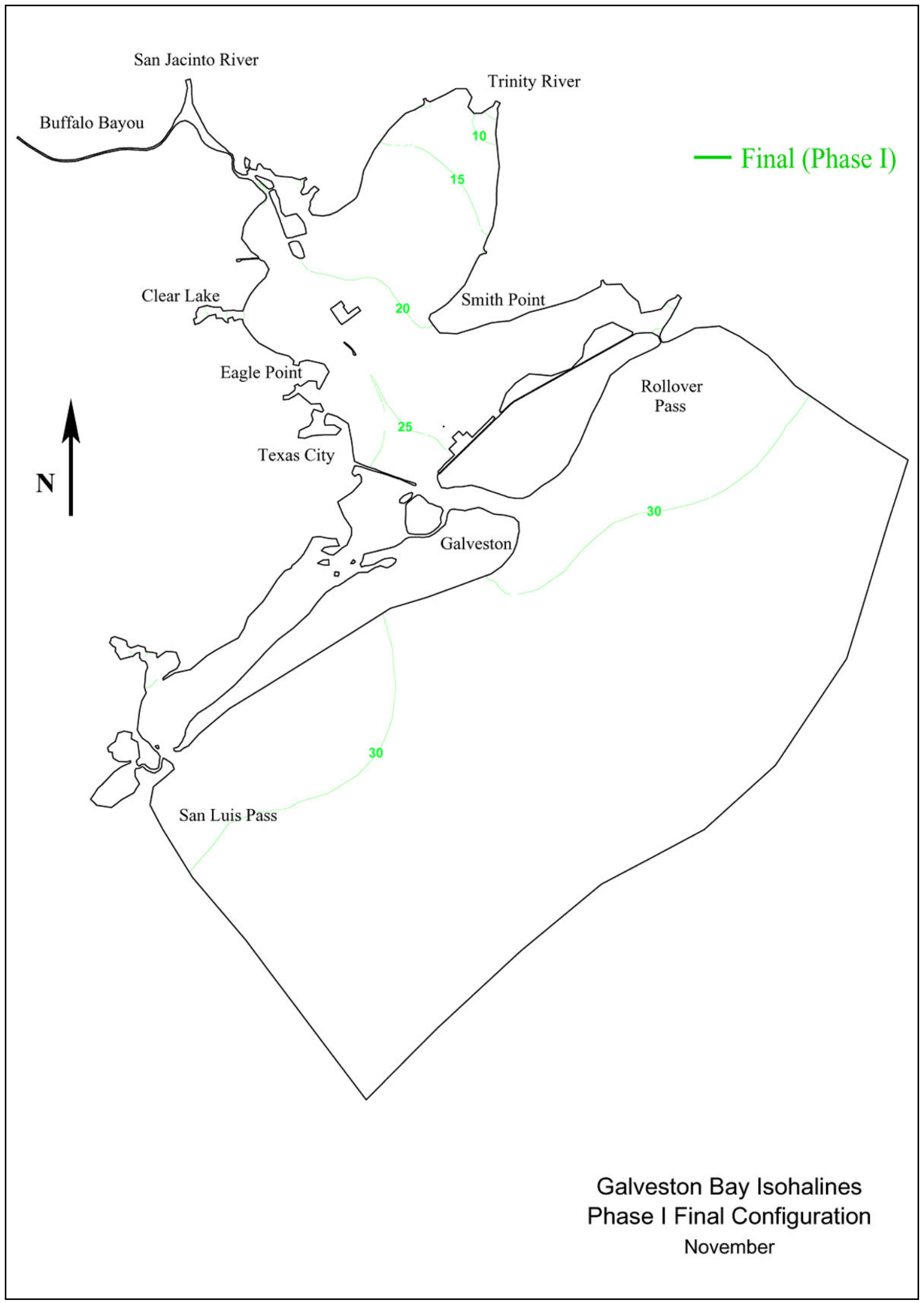

Plate 12 


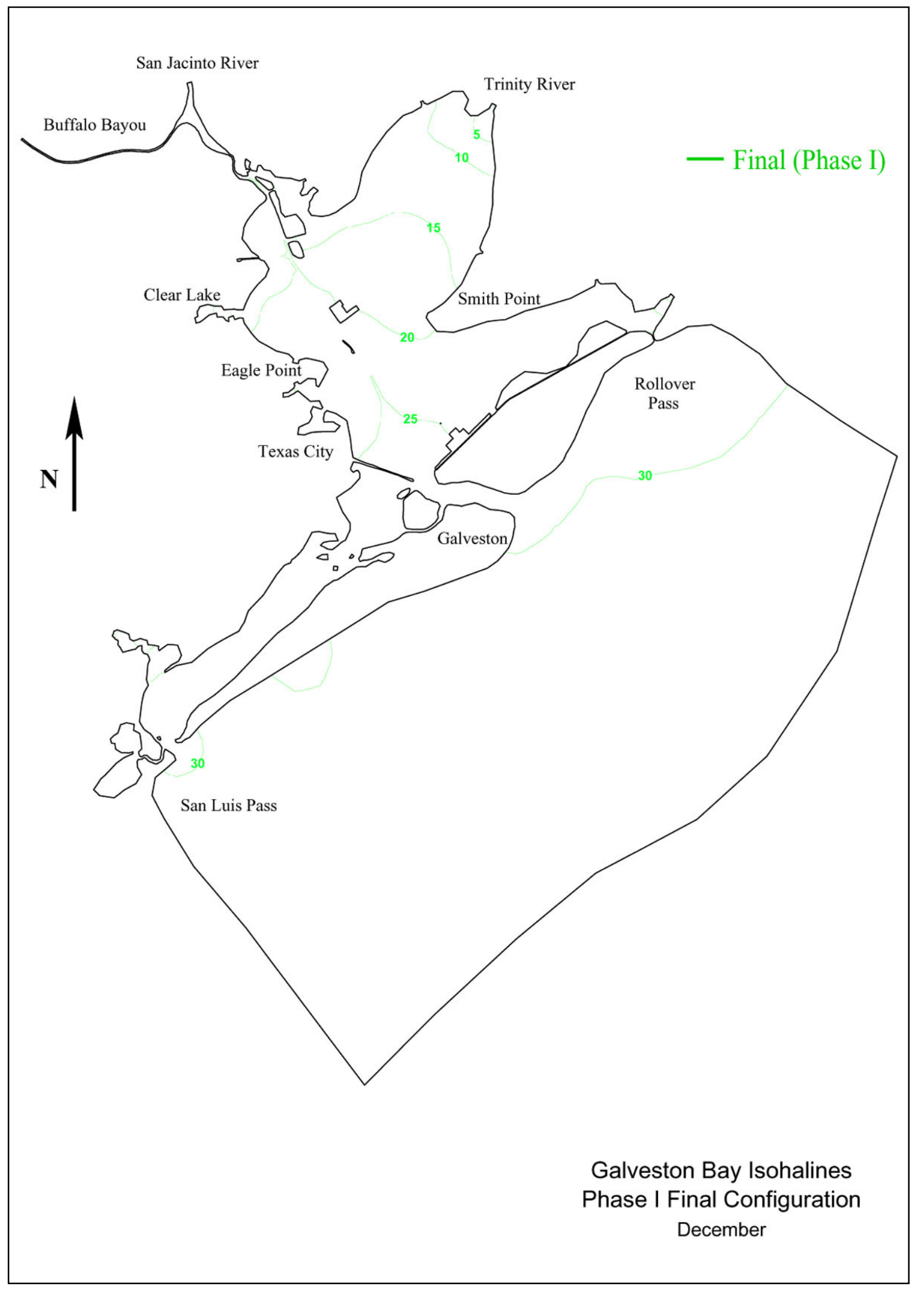

Plate 13 


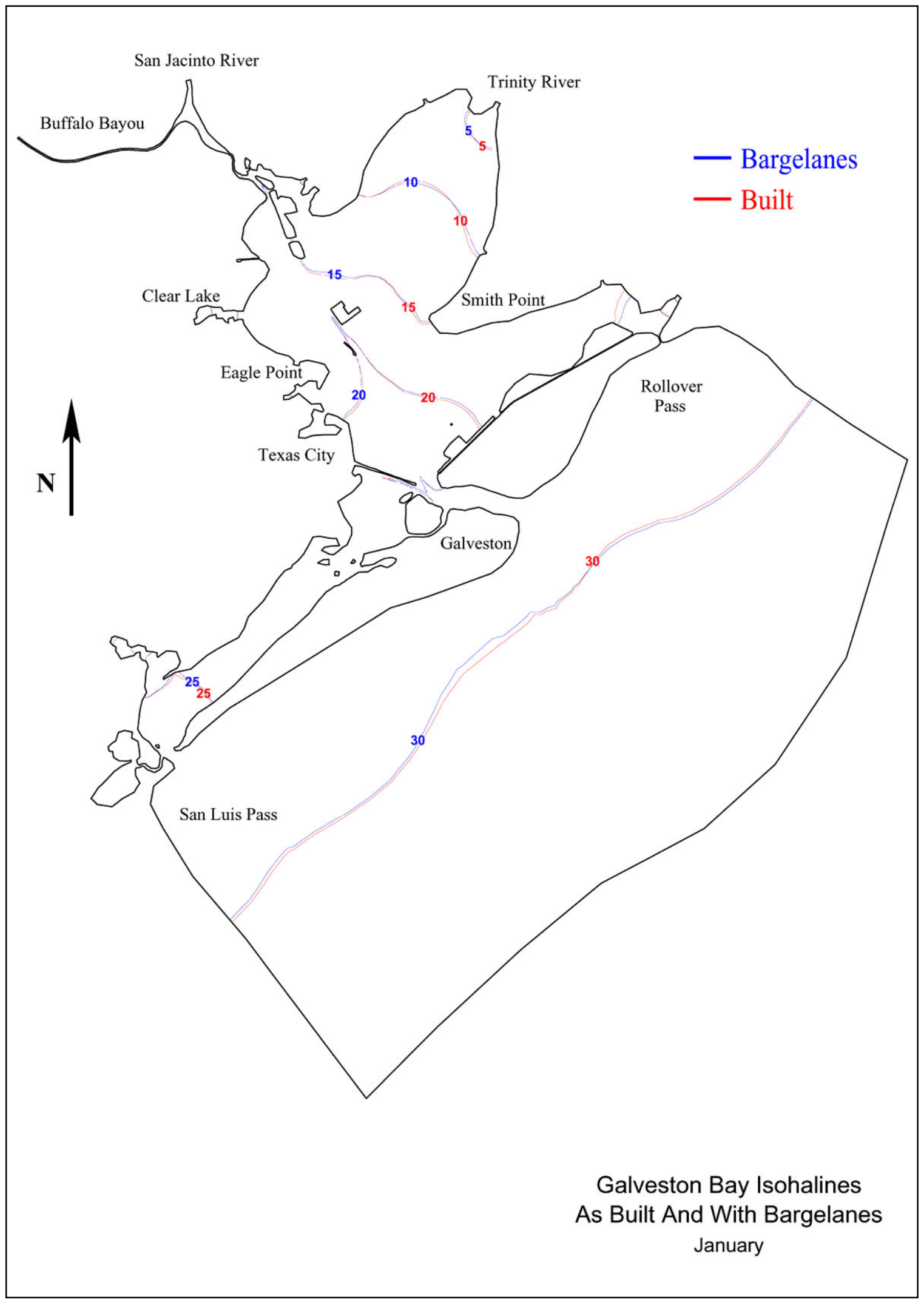

Plate 14 


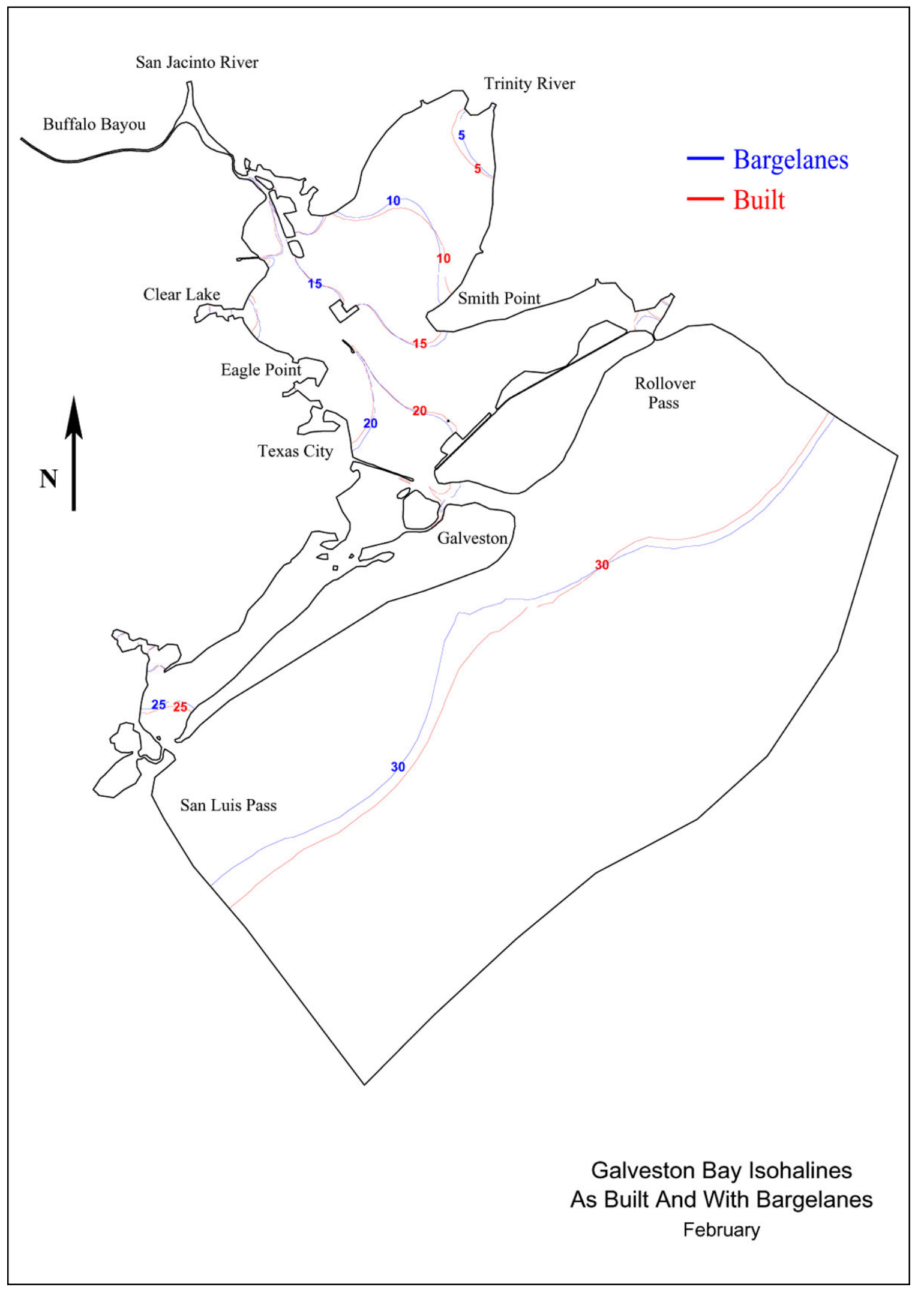

Plate 15 


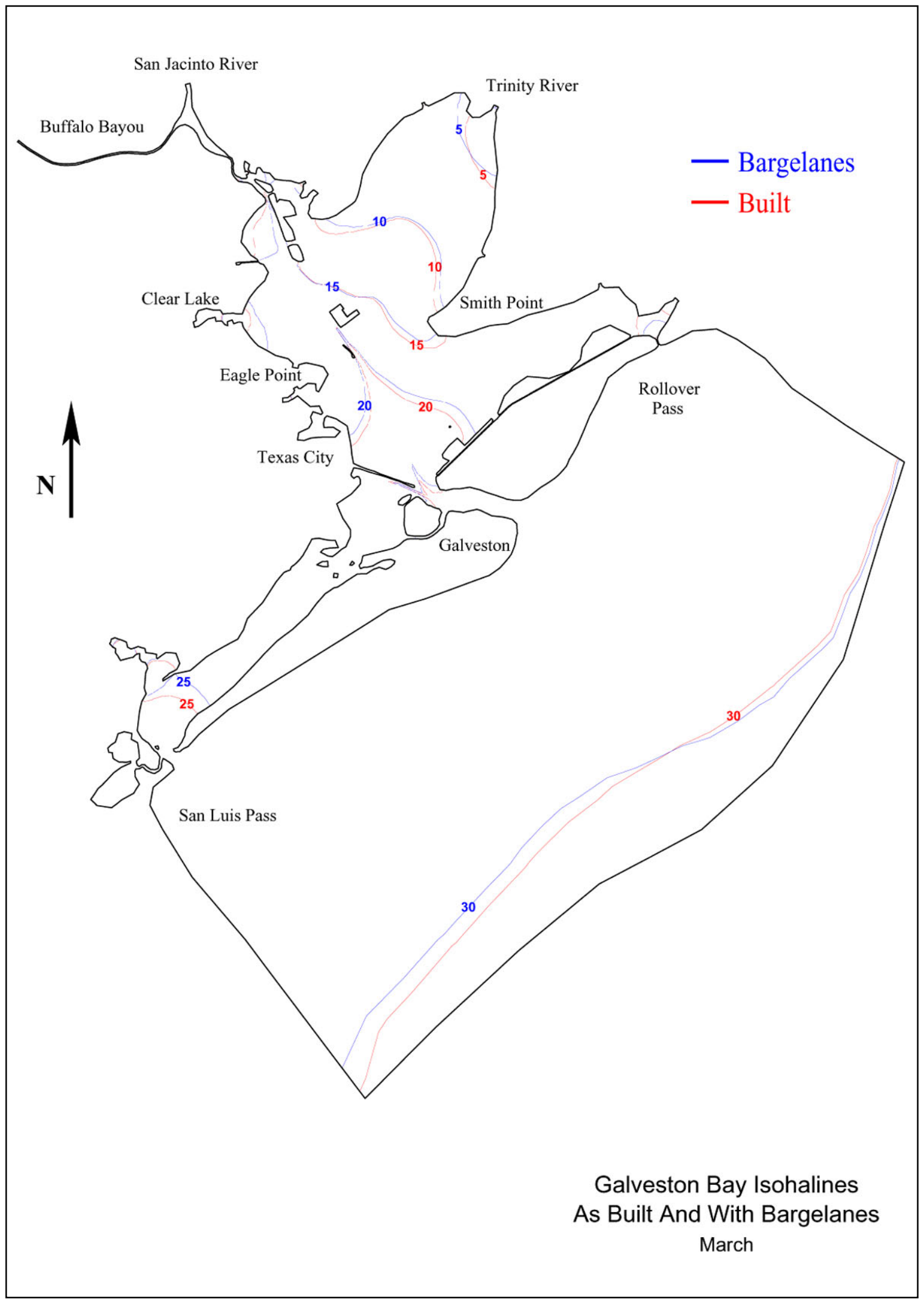

Plate 16 


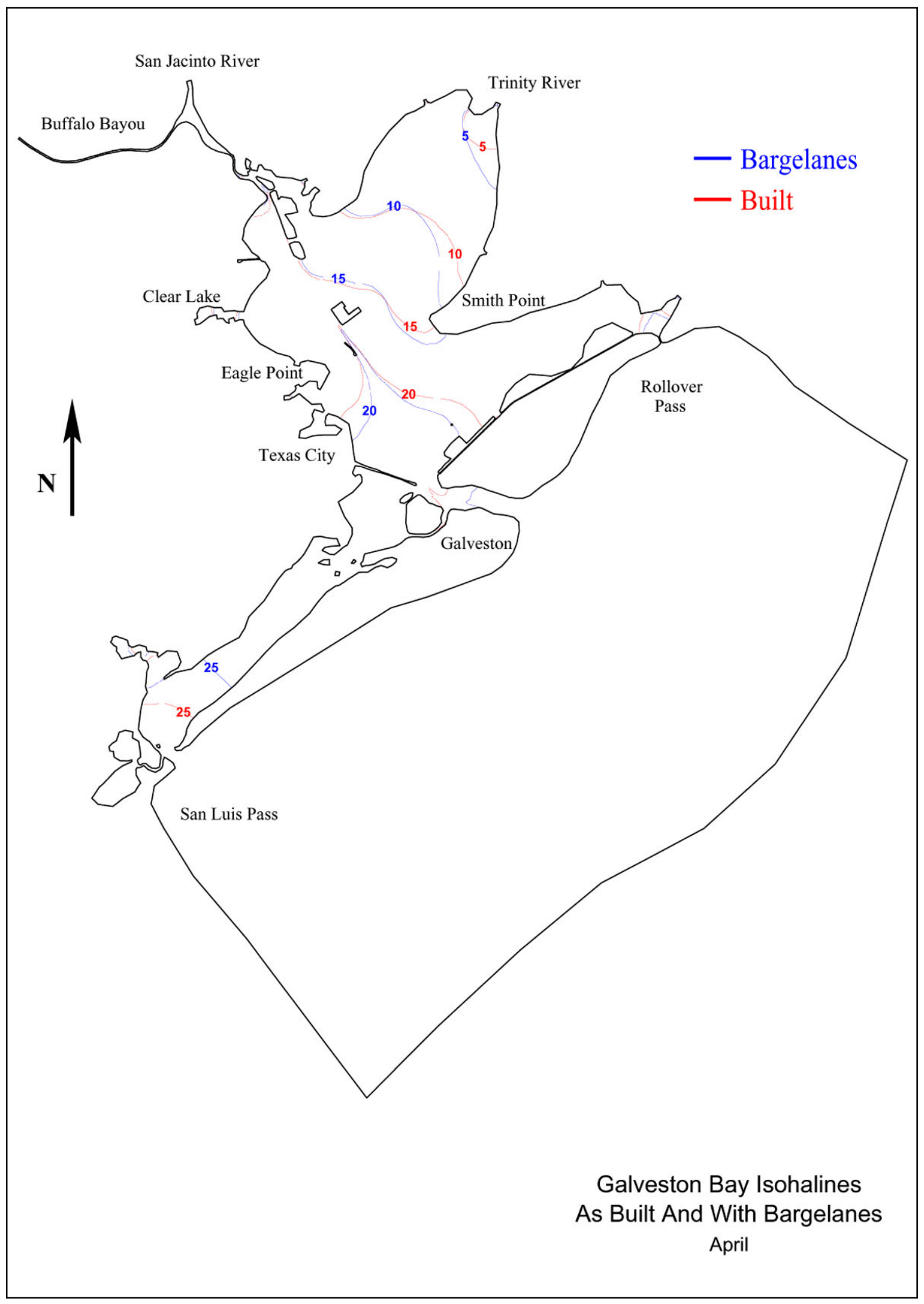

Plate 17 


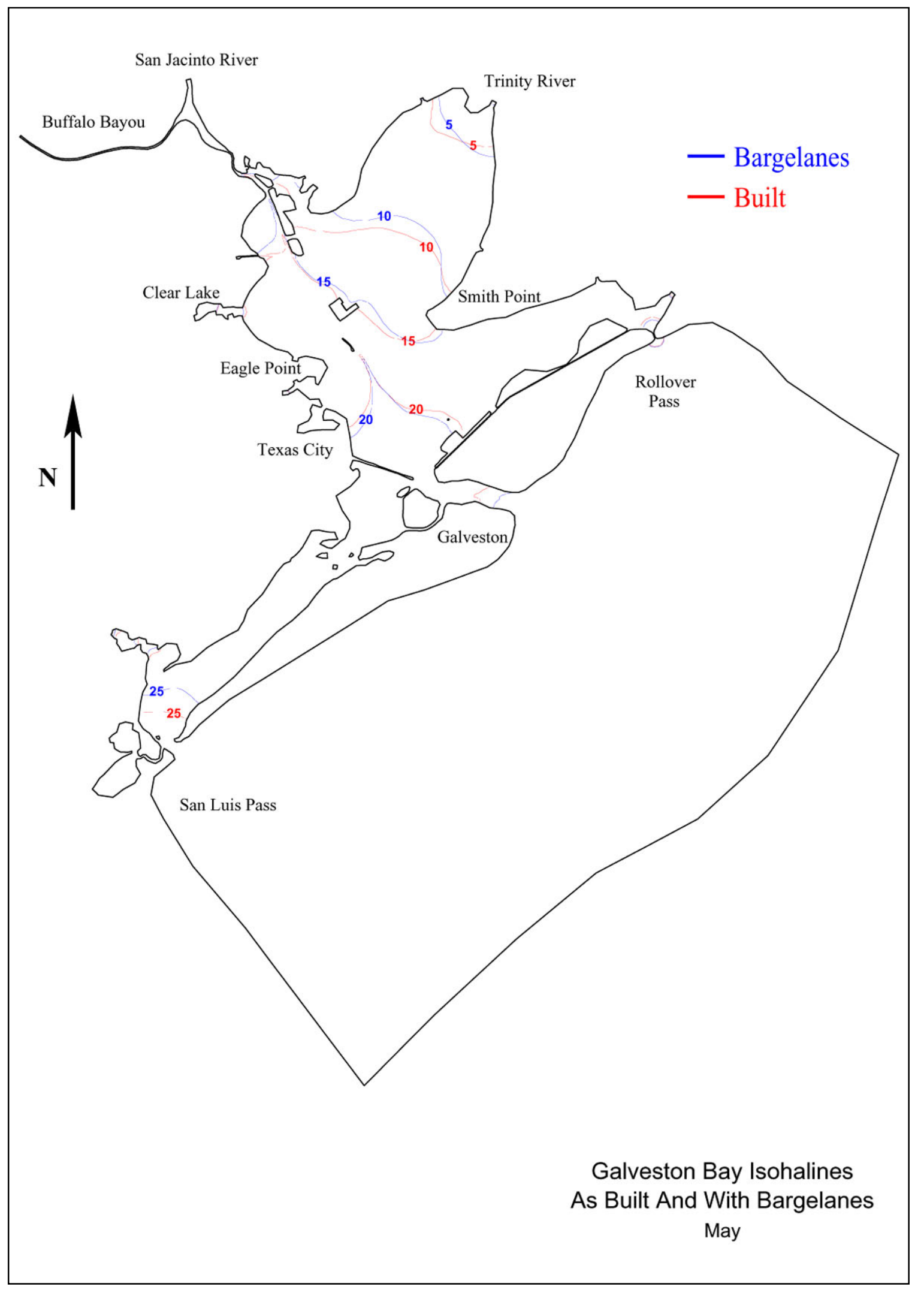

Plate 18 


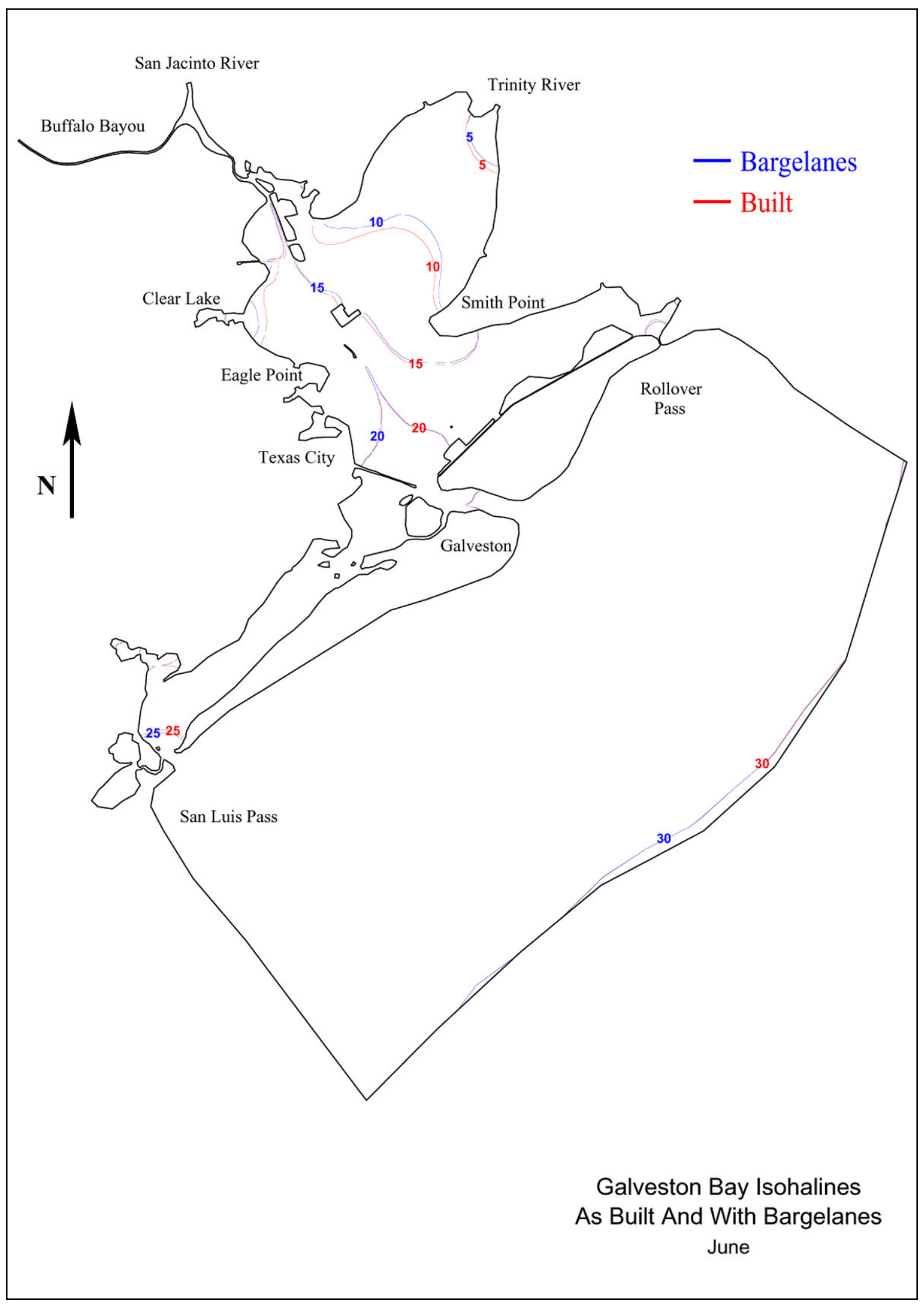

Plate 19 


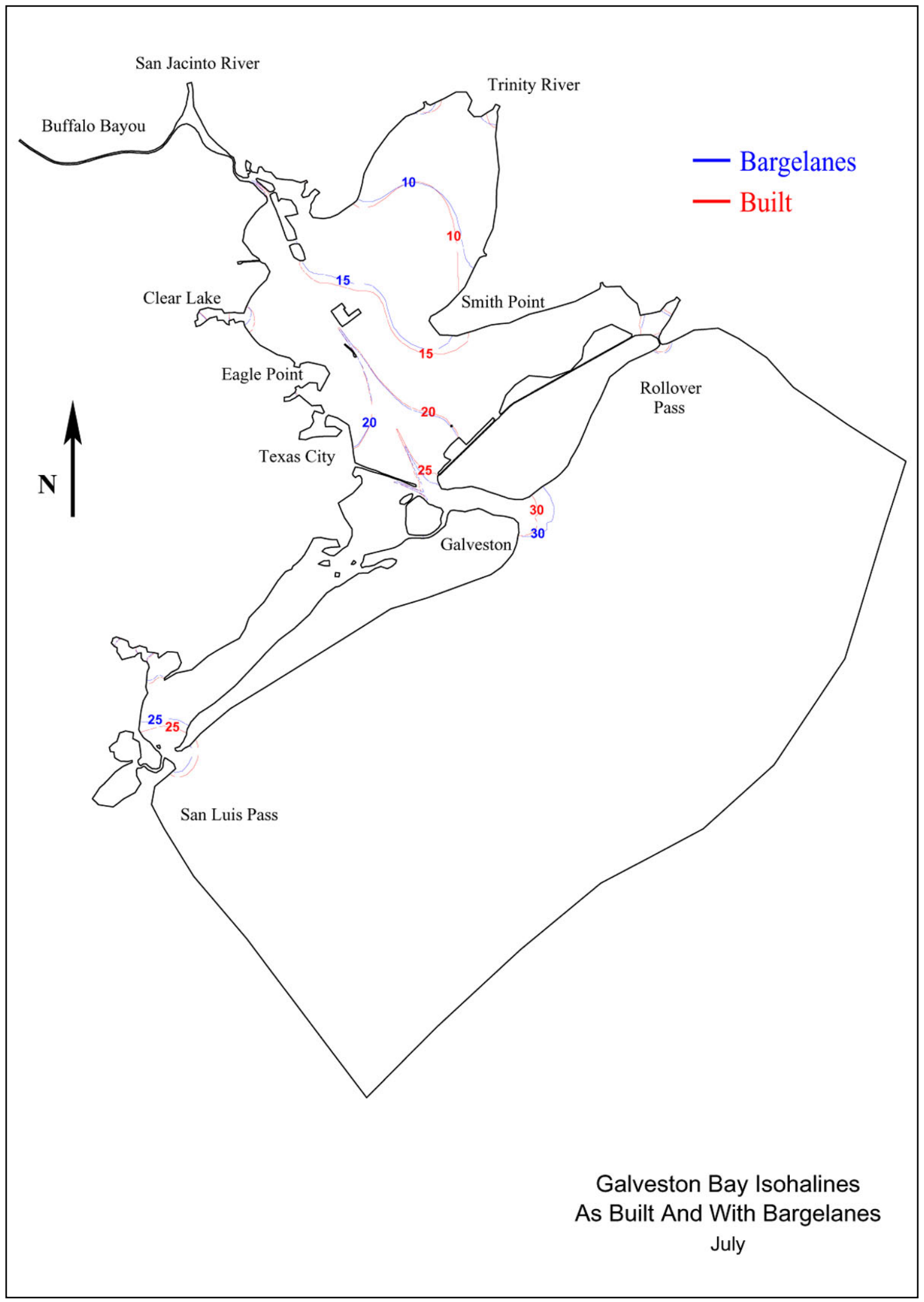

Plate 20 


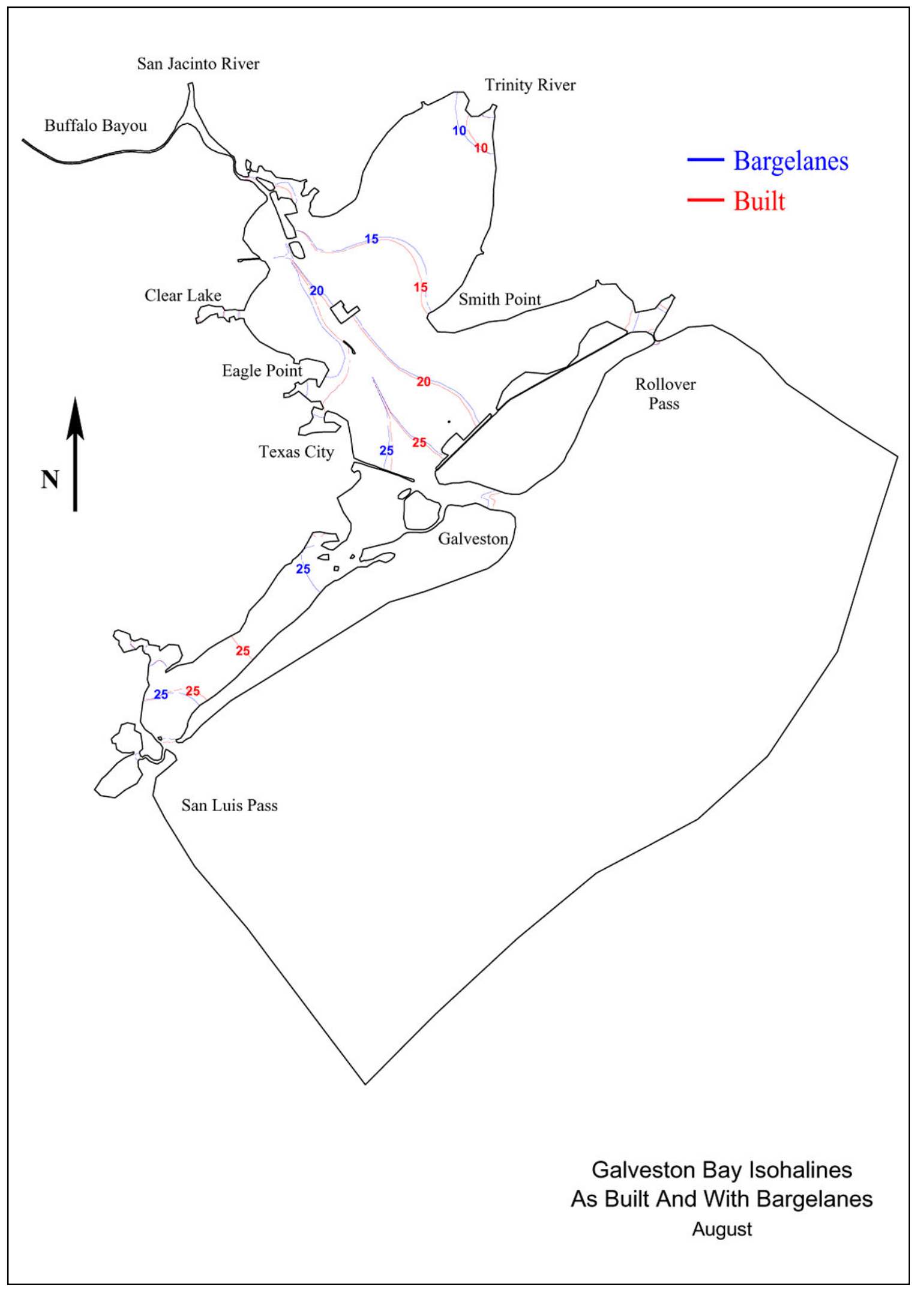

Plate 21 


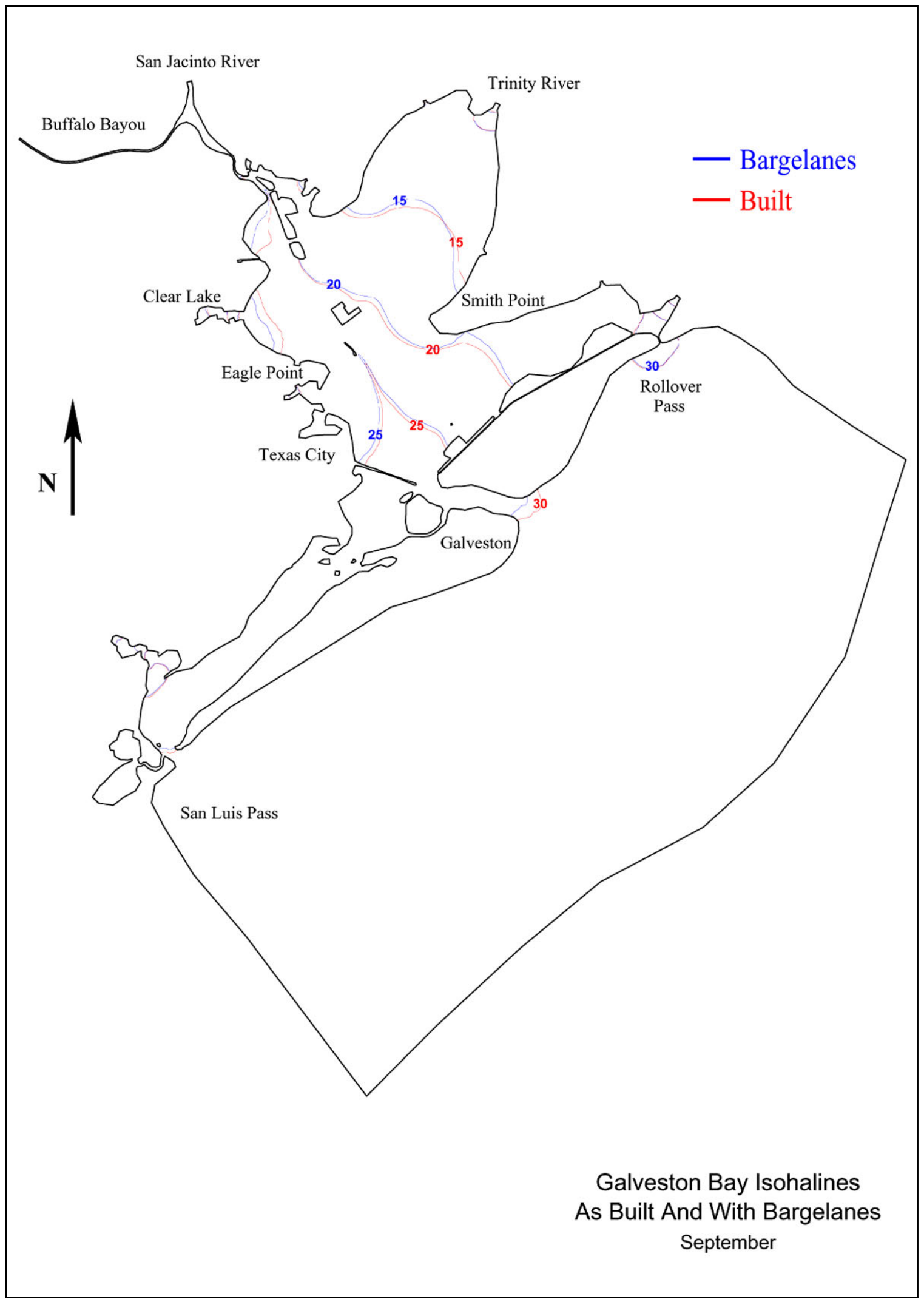

Plate 22 


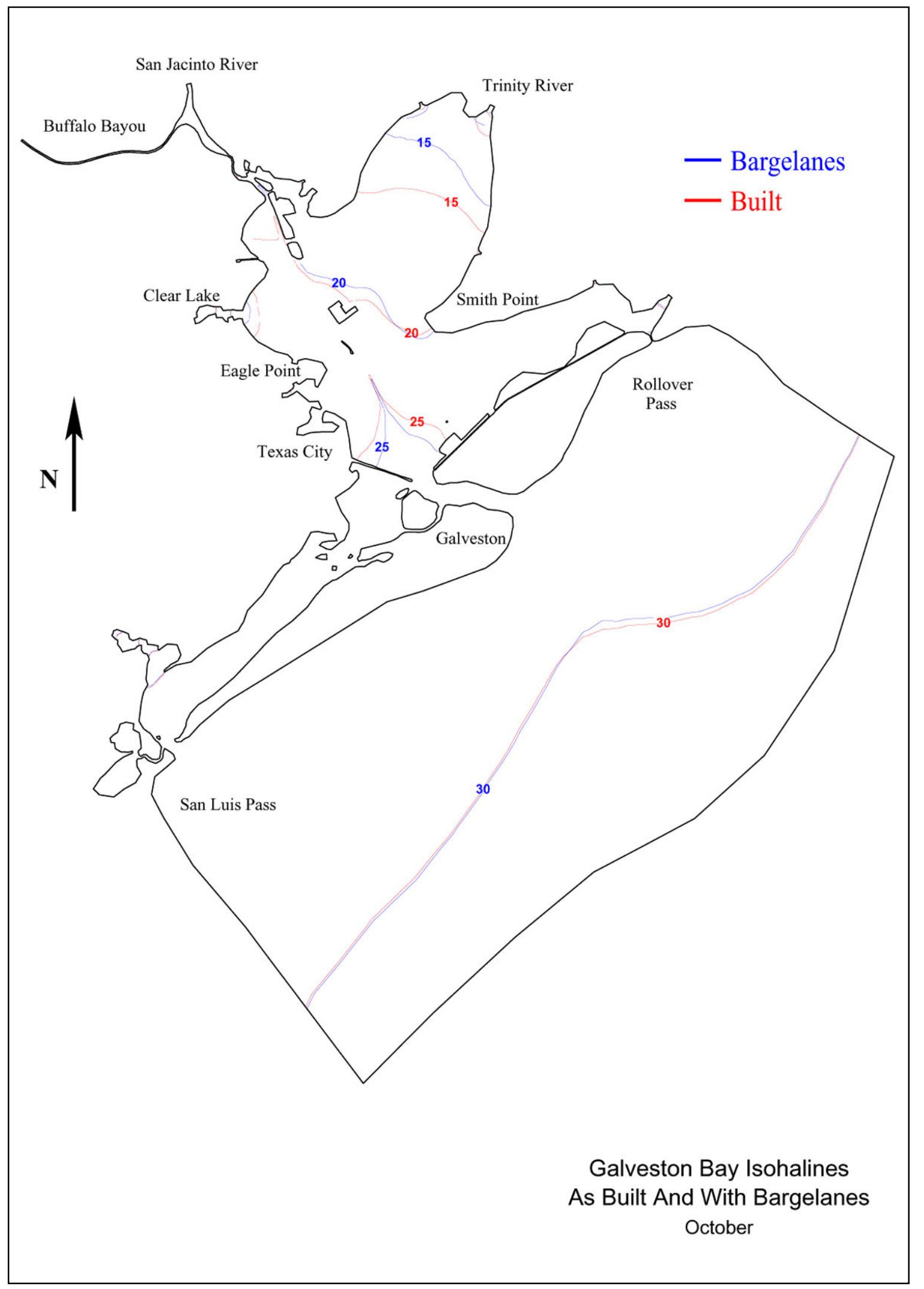

Plate 23 


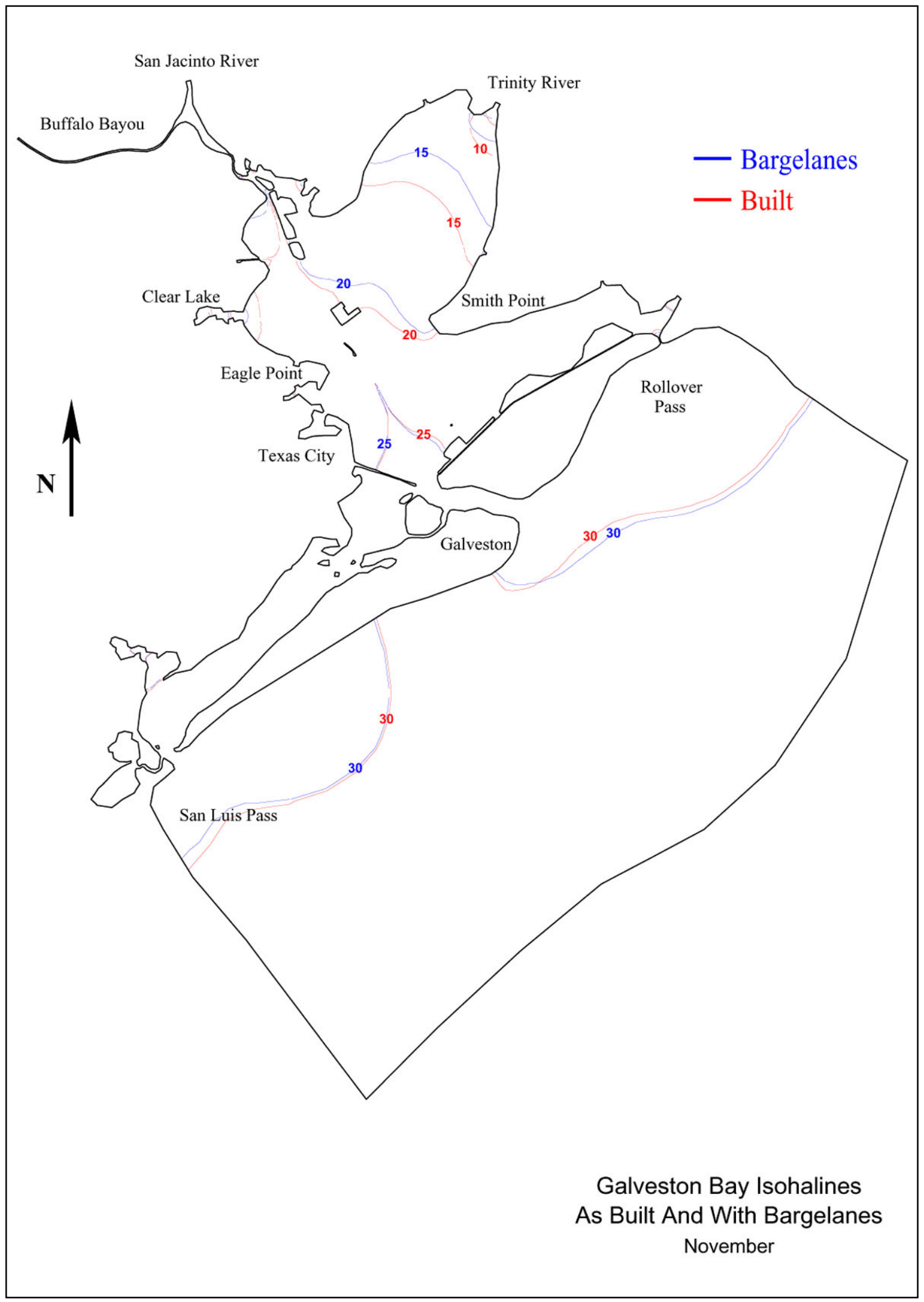

Plate 24 


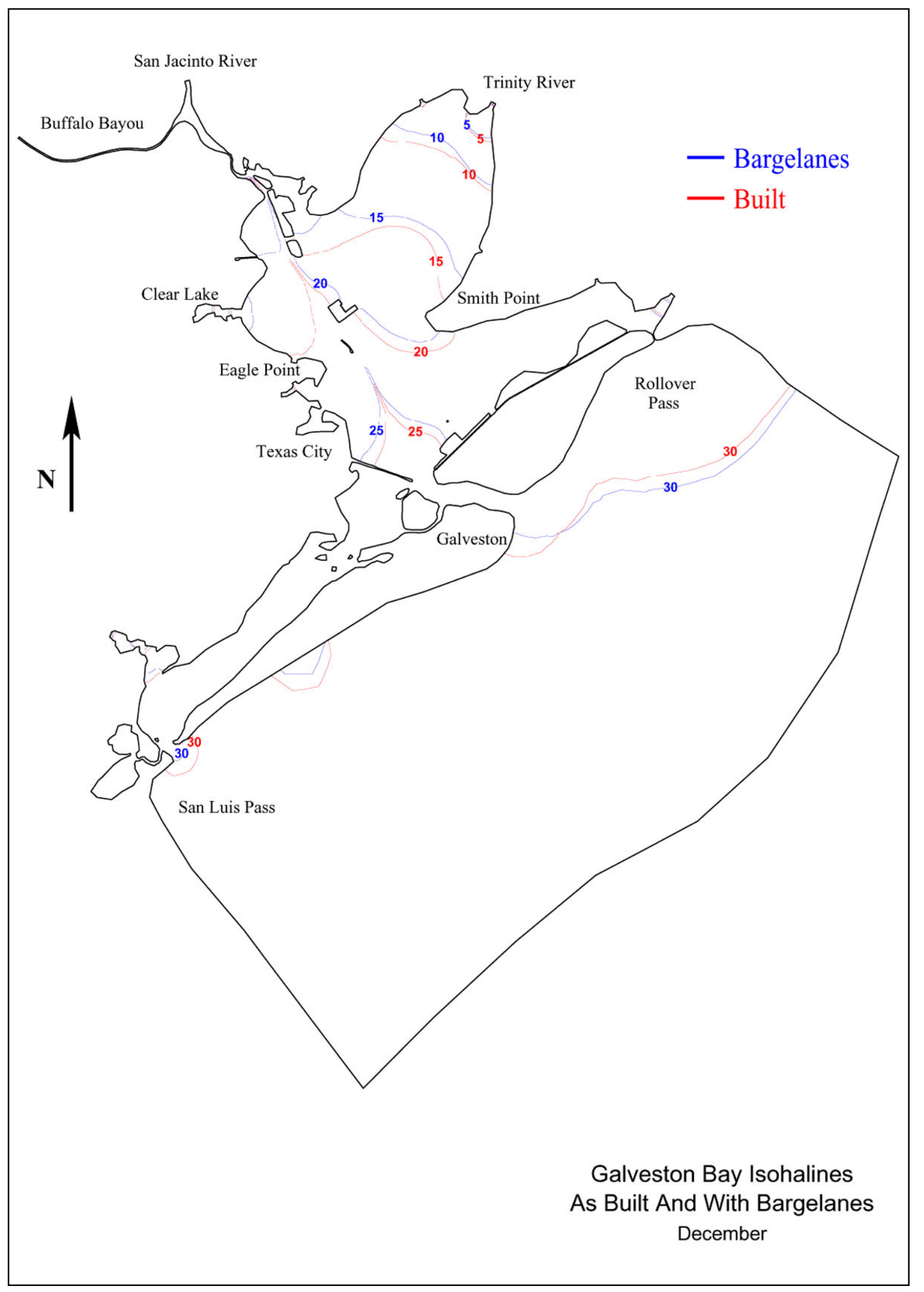

Plate 25 


\section{Appendix A Hydrodynamic Code}

The complexity of this estuary requires a numerical model that relies upon an unstructured computational mesh. The code chosen is the Galerkin-based finite element model TABS-MDS, which is a U.S. Army Engineer Research and Development Center (ERDC) adaptation of the RMA-10 code developed by King (1993). ${ }^{1}$ This code computes time-varying open-channel flow and salinity/ temperature transport in one, two, and three dimensions. It invokes the hydrostatic pressure and mild slope assumption. Vertical turbulence is supplied using a Mellor-Yamada Level II (Mellor and Yamada 1982) $k$ - $\ell$ approach modified for stratification by the method of Henderson-Sellers (1984). The salinity/density relationship is based upon Pritchard (1982).

The full 3-D equations are reduced to a set of two momentum equations, an integrated continuity equation, a convection-diffusion equation, and an equation of state. The simplification is a result of the hydrostatic pressure approximation.

$$
\begin{aligned}
& \rho \frac{D u}{D t}-\nabla \cdot \sigma_{x}+\frac{\partial \mathrm{P}}{\partial x}-\Gamma_{x}=0 \\
& \rho \frac{D v}{D t}-\nabla \cdot \sigma_{y}+\frac{\partial \mathrm{P}}{\partial y}-\Gamma_{y}=0 \\
& \frac{\partial h}{\partial t}+u_{\zeta} \frac{\partial \zeta}{\partial x}-u_{a} \frac{\partial a}{\partial x}+v_{\zeta} \frac{\partial \zeta}{\partial y}-v_{a} \frac{\partial a}{\partial y}+\int_{a}^{\zeta}\left(\frac{\partial u}{\partial x}+\frac{\partial v}{\partial y}\right) d z=0 \\
& \frac{D s}{D t}-\frac{\partial}{\partial x}\left(D_{x} \frac{\partial s}{\partial x}\right)-\frac{\partial}{\partial y}\left(D_{y} \frac{\partial s}{\partial y}\right)-\frac{\partial}{\partial z}\left(D_{z} \frac{\partial s}{\partial z}\right)=0
\end{aligned}
$$

\footnotetext{
${ }^{1}$ All references cited in this appendix are listed in the References section at the end of the main text.
} 


$$
\rho=F(s)
$$

Elevation-related terms are defined in Figure A1.

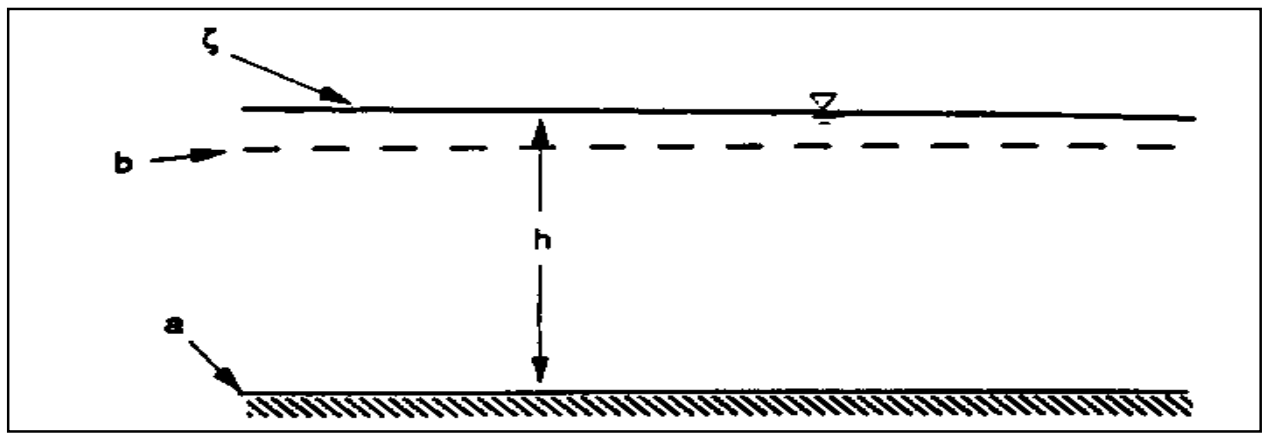

Figure A1. Definitions for elevation terms

where

$$
\sigma_{x}=\left\{\begin{array}{ll}
E_{x x} & \frac{\partial u}{\partial x} \\
E_{x y} & \frac{\partial u}{\partial y} \\
E_{x z} & \frac{\partial u}{\partial z}
\end{array}\right\} ; \quad \sigma_{y}=\left\{\begin{array}{cc}
E_{y x} & \frac{\partial v}{\partial x} \\
E_{y y} & \frac{\partial v}{\partial y} \\
E_{y z} & \frac{\partial v}{\partial z}
\end{array}\right\}
$$

and

$$
\begin{aligned}
\rho & =\text { density } \\
u, v, w & =\mathrm{x}, \mathrm{y}, \mathrm{z} \text { velocity components } \\
t & =\text { time } \\
P & =\text { pressure } \\
\Gamma_{x} & =\rho \Omega v-\frac{\rho g u_{a}\left(u_{a}^{2}+v_{a}^{2}\right)^{(1 / 2)}}{C^{2}}+\psi W^{2} \cos (\Theta) \\
\Gamma_{y} & =-\rho \Omega u-\frac{\rho g v_{a}\left(u_{a}^{2}+v_{a}^{2}\right)^{(1 / 2)}}{C^{2}}+\psi W^{2} \sin (\Theta) \\
\Omega & =2 \omega \sin (\varphi) \\
\omega & =\text { rate of angular rotation of the earth } \\
\varphi & =\text { local latitude } \\
g & =\text { gravitational acceleration } \\
C & =\text { Chezy or Manning friction formulation } \\
\psi & =\text { a coefficient from Wu (1980) } \\
W & =\text { wind speed } \\
\Theta & =\text { wind direction counterclockwise from easterly }
\end{aligned}
$$




$$
\begin{aligned}
h & =\text { depth } \\
u_{\zeta}, v_{\zeta} & =x, y \text { velocity components at the water surface } \\
\zeta & =\text { water-surface elevation } \\
u_{a}, v_{a} & =x, y \text { velocity at the bed } \\
a & =\text { bed elevation } \\
s & =\text { salinity } \\
D_{x}, D_{y}, D_{z} & =\text { diffusion coefficient for salt } \\
E & =\text { eddy viscosity components }
\end{aligned}
$$

The continuity equation

$$
\frac{\partial u}{\partial x}+\frac{\partial v}{\partial y}+\frac{\partial_{w}}{\partial z}=0
$$

is solved as a second part of each solution step. Equation A6 is converted to an appropriate boundary value problem through differentiation with respect to $z$. After rearrangement it takes the form

$$
\frac{\partial^{2} w}{\partial z^{2}}=-\frac{\partial}{\partial z}\left(\frac{\partial u}{\partial x}+\frac{\partial v}{\partial y}\right)
$$

subject to boundary conditions specified for the water surface and the bed.

$$
w_{\zeta}=u_{\zeta} \frac{\partial \zeta}{\partial x}+v_{\zeta} \frac{\partial \zeta}{\partial y}+\frac{\partial h}{\partial t} \quad \text { at the water suface }
$$

and

$$
w_{a}=u_{a} \frac{\partial a}{\partial x}+v_{a} \frac{\partial a}{\partial y} \text { at the bed }
$$

Note that in these equations the values of $u$ and $v$ will be known at all locations from the previous part of the solution step. Values of $w$ in this solution are used in the next iteration for $u, v, h$, and $s$.

The geometric system varies with time; i.e., the water depth $h$ varies during the simulation. In order to develop an Eulerian form for the solution, it is desirable to transform this system to one that can be described with a constant geometric structure. Early development of the model (King 1982) used a $\sigma$ transformation in which the bed and the water surface are transformed to constants. In a later analysis of this method, King (1985) pointed out that at locations where a sharp break in bottom profile occurs, the transformation is not unique and momentum in the component directions may not be correctly preserved. An alternative transformation that preserves the bottom profile as defined, but 
transforms the water surface to a constant elevation is now used $\left(z^{\nabla}\right.$ transformation).

This transformation is defined by:

$$
\begin{aligned}
& x^{\nabla}=x \\
& y^{\nabla}=y \\
& z^{\nabla}=a+(z-a) \frac{(b-a)}{h}
\end{aligned}
$$

where $b$ is the fixed vertical location to which the water surface will be transformed. Equations A1-A6 and A7-A9 then incorporate the transformation (A10A12).

Another advantage of this transformation is that it produces $z^{\nabla}=$ constant lines that are close to horizontal, i.e., $z=$ constant lines. This results in less fictitious density-driven currents near bed profile breaks (Stelling and van Kester 1993). Since stratification-related phenomena are usually nearly horizontal, it is important that the transformation leave constant surfaces that are nearly horizontal. Considering the pressure gradient (due to the density gradient) in this transformation produces

$$
\frac{\partial P}{\partial x}=\frac{\partial P}{\partial x^{\nabla}}+\frac{\partial P}{\partial z^{\nabla}} \frac{\partial z^{\nabla}}{\partial x}
$$

In a strongly stratified stagnant system this pressure gradient should be zero. However, note that Equation A13 in the transformed system is dependent upon two terms (each of which could be large) to cancel each other. This could cause artificial currents due to truncation and round-off error. A transformation in which $\partial z^{\nabla} / \partial x \approx 0$, i.e., $z^{\nabla} \approx z$, will reduce this problem. Figure A2 shows an example for a case in which a 40-ft-deep channel passes through an 8-ft-deep bay. Here $b$ is chosen to be an elevation of 0 and $\zeta$ is $2 \mathrm{ft}$. Near the break in the bed profile $\partial z^{\nabla} / \partial x$ is fairly small, or $z^{\nabla}$ surfaces are nearly horizontal. Contrast this with the $\sigma$ transformation in Figure A3. The $\sigma=$ constant surfaces are far from horizontal along the channel side slopes. The truncation and round-off errors tend to drive fictitious currents that cause the denser salt water to leave the channel. The $z^{\nabla}$ transformation results in

$$
\frac{\partial z^{\nabla}}{\partial x}=0(\zeta-b)
$$


whereas the $\sigma$ transformation is

$$
\frac{\partial \sigma}{\partial x}=O(h)
$$

which is much larger.

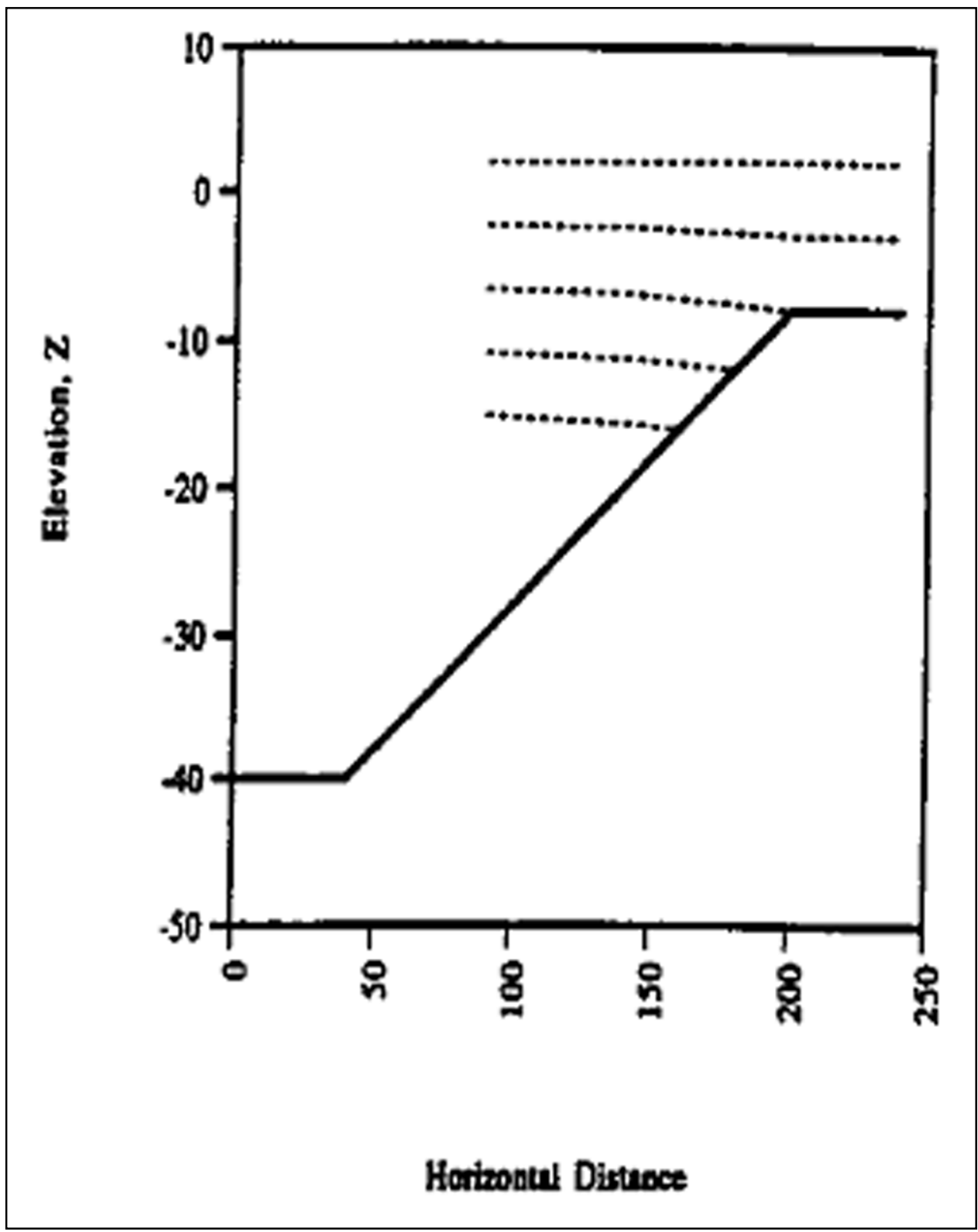

Figure A2. Lines of constant $z^{\nabla}$ near a significant grade change 


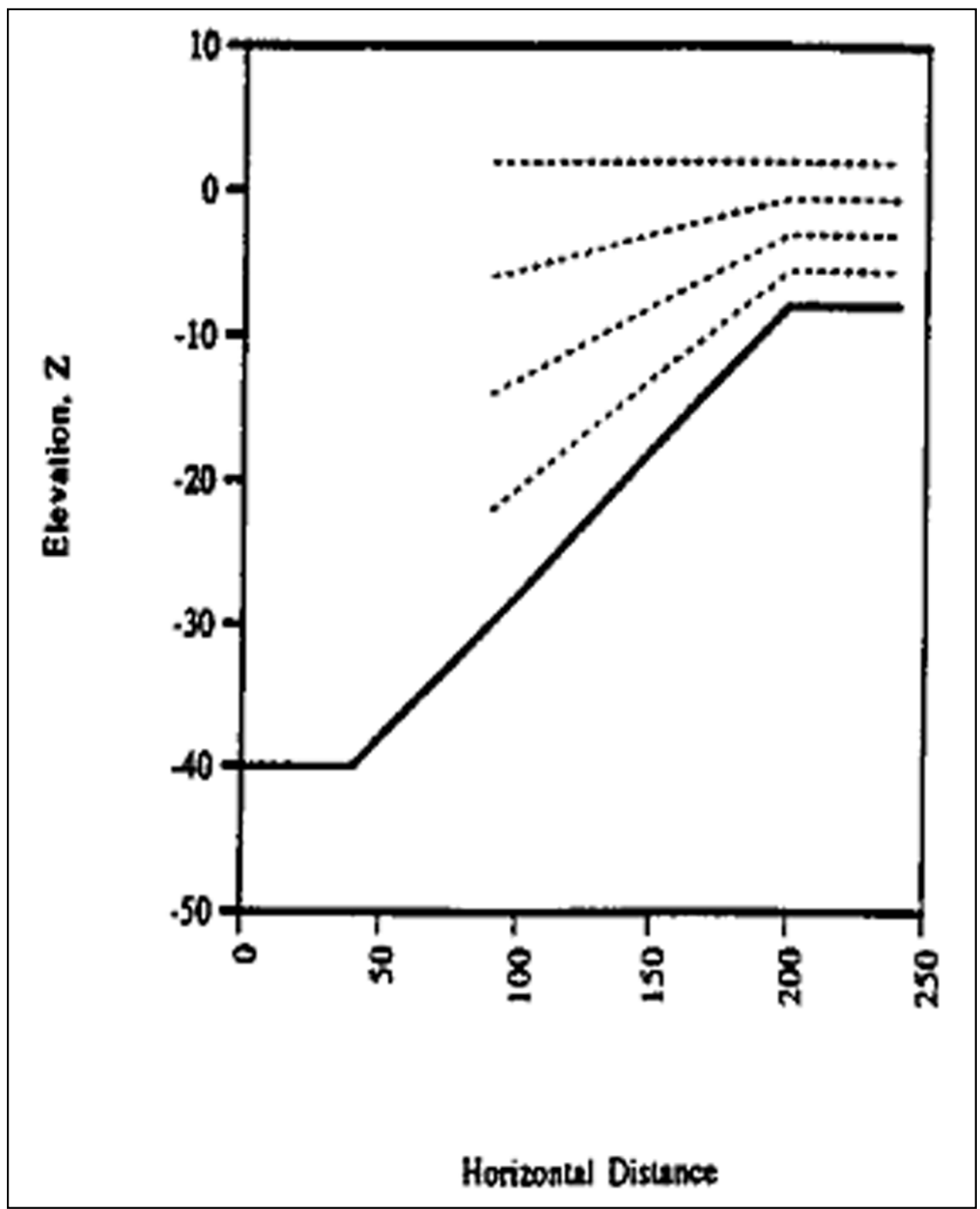

Figure A3. Lines of constant $\sigma$ near a significant grade change

The Galerkin finite element approximation of Equations A1-A4 and A7 uses a quadratic approximation for $u, v, w$, and $s$ and linear for $h$ and $P$. The nonlinearity is addressed by Newton-Raphson iteration at each time-step. Generally the iteration process is split into calculation of Equations A1-A3, then A7, followed by A4. This sequence is repeated until sufficient convergence is reached. 


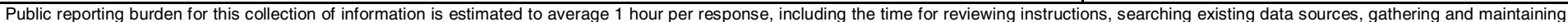

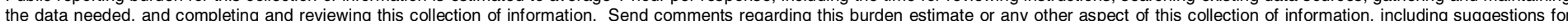

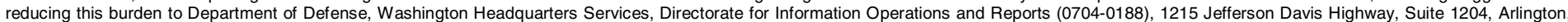

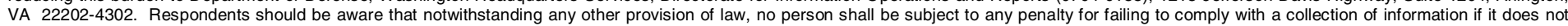
display a currently valid OMB control number. PLEASE DO NOT RETURN YOUR FORM TO THE ABOVE ADDRESS.

\begin{tabular}{l|c}
$\begin{array}{l}\text { 1. REPORT DATE }(D D-M M-Y Y Y Y) \\
\text { September } 2002\end{array}$ & $\begin{array}{c}\text { 2. REPORT TYPE } \\
\text { Final report }\end{array}$ \\
\hline
\end{tabular}

4. TITLE AND SUBTITLE

Effects of Adding Barge Lanes Along Houston Ship Channel

Through Galveston Bay, Texas

3. DATES COVERED (From - To)

5a. CONTRACT NUMBER

5b. GRANT NUMBER

5c. PROGRAM ELEMENT NUMBER

6. AUTHOR(S)

5d. PROJECT NUMBER

Alex R. Carrillo, M. Soraya Sarruff, R. C. Berger

5e. TASK NUMBER

5f. WORK UNIT NUMBER

7. PERFORMING ORGANIZATION NAME(S) AND ADDRESS(ES)

8. PERFORMING ORGANIZATION REPORT NUMBER

U.S. Army Engineer Research and Development Center

Coastal and Hydraulics Laboratory

ERDC/CHL TR-02-23

3909 Halls Ferry Road

Vicksburg, MS 39180-6199

9. SPONSORING / MONITORING AGENCY NAME(S) AND ADDRESS(ES)

10. SPONSOR/MONITOR'S ACRONYM(S)

U.S. Army Engineer District, Galveston

P.O. Box 1229

Galveston, TX 77553-1229

11. SPONSOR/MONITOR'S REPORT NUMBER(S)

\section{DISTRIBUTION / AVAILABILITY STATEMENT}

Approved for public release; distribution is unlimited.

\section{SUPPLEMENTARY NOTES}

\section{ABSTRACT}

The U.S. Army Engineer District, Galveston, is making an environmental assessment of the addition of barge lanes along the Houston Ship Channel through Galveston Bay. The proposed barge lanes are to allow barge traffic to safely coexist with the deep-draft navigation. In support of this assessment, the Galveston District requested that the Galveston Bay numerical model developed by the U.S. Army Engineer Research and Development Center, Coastal and Hydraulics Laboratory, be used to predict the month-average salinity changes that will occur in Galveston Bay resulting from the addition of the proposed barge lanes. This report presents the results of that numerical model investigation.

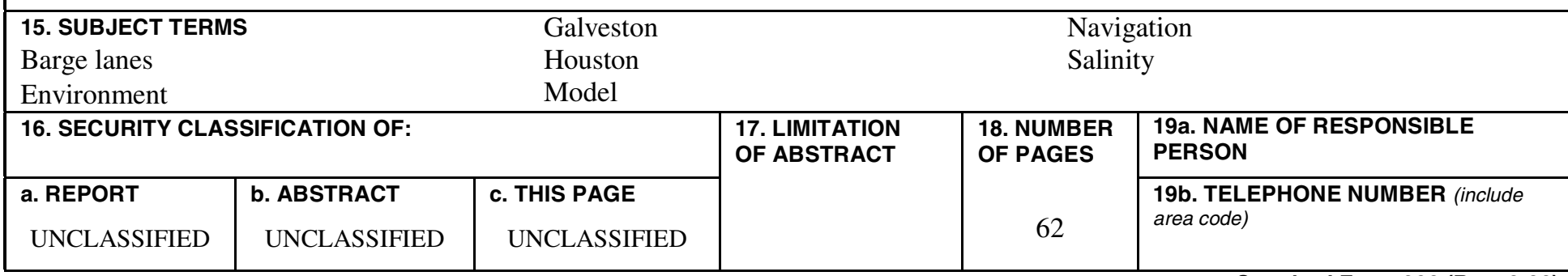

